\title{
Post-CCSD(T) contributions to total atomization energies in multireference systems
}

\author{
Amir Karton ${ }^{*}$ \\ School of Molecular Sciences, The University of Western Australia, Perth, WA 6009, \\ Australia.
}

\begin{abstract}
We examine the magnitude and basis set convergence of post-CCSD(T) contributions (up to CCSDTQ567) for a wide and diverse set of 21 first- and second- row molecules with up to four non-hydrogen atoms. We focus on multireference systems for which post-CCSD(T) effects are particularly pronounced. The considered molecules are $\mathrm{BN}\left({ }^{1} \Sigma^{+}\right), \mathrm{C}_{2}\left({ }^{1} \Sigma^{+}\right), \mathrm{O}_{2}, \mathrm{FO}, \mathrm{P}_{2}, \mathrm{~S}_{2}, \mathrm{ClO}, \mathrm{N}_{2} \mathrm{O}, \mathrm{NO}_{2}, \mathrm{O}_{3}, \mathrm{FNO}, \mathrm{FO}_{2}, \mathrm{~F}_{2} \mathrm{O}, \mathrm{S}_{2} \mathrm{O}, \mathrm{S}_{3}, \mathrm{ClNO}, \mathrm{ClOO}$, $\mathrm{Cl}_{2} \mathrm{O}, \mathrm{N}_{2} \mathrm{C}_{2}, \mathrm{P}_{4}$, and $\mathrm{S}_{4}$. This set spans the gamut from molecules dominated by moderate nondynamical correlation (e.g., $\mathrm{FO}, \mathrm{ClO}, \mathrm{NO}_{2}, \mathrm{~S}_{2} \mathrm{O}, \mathrm{N}_{2} \mathrm{C}_{2}$, and $\mathrm{P}_{4}$ ) to systems dominated by strong nondynamical correlation (e.g., $\mathrm{BN}, \mathrm{C}_{2}, \mathrm{FO}_{2}, \mathrm{O}_{3}, \mathrm{ClOO}$, and $\mathrm{S}_{4}$ ). We examine the basis set convergence of the CCSDT, CCSDT(Q), CCSDTQ, CCSDTQ(5), CCSDTQ5,
\end{abstract} CCSDTQ5(6), CCSDTQ56, CCSDTQ56(7), and CCSDTQ567 methods. The largest basis set employed in each category are: cc-pV6Z (CCSDT(Q)), cc-pV5Z (CCSDTQ), cc-pVTZ (CCSDTQ5(6)), and cc-pVDZ (CCSDTQ567). Apart from examining the basis-set convergence of post-CCSD(T) contributions near the one-particle basis-set limit, this work explores cost-effective approaches for obtaining these contributions from fairly small basis sets. We consider both effective basis-set extrapolations and scaling factors. An important finding is that extrapolating the perturbative connected quadruples, $(\mathrm{Q})$, from the cc$\mathrm{pVDZ}(4 \mathrm{~s} 3 \mathrm{p} 1 \mathrm{~d})$ and cc-pVTZ basis sets yields near basis-set limit results and represents a significant improvement relative to $\mathrm{cc}-\mathrm{pV}\{\mathrm{D}, \mathrm{T}\} \mathrm{Z}$ extrapolation at no additional 
computational cost (where cc-pVDZ(4s3p1d) is an extended version of the cc-pVDZ basis set). Combining the $(\mathrm{Q}) / \mathrm{cc}-\mathrm{pV}\{\mathrm{D}(4 \mathrm{~s} 3 \mathrm{p} 1 \mathrm{~d}), \mathrm{T}\} \mathrm{Z}$ extrapolations with the fully iterative connected quadroples, Q- $(\mathrm{Q})$, contribution calculated with the cc-pVDZ (or even the cc$\mathrm{pVDZ}(3 \mathrm{~s} 2 \mathrm{p}))$ basis set is a very cost-effective way for obtaining the connected quadruples component close to the basis-set limit (where cc-pVDZ(3s2p) is a truncated version of the ccpVDZ basis set). In addition, we show that the (5)/cc-pVDZ(3s $2 p)$ and (6)/cc-pVDZ(3s2p) components provide reasonable approximations for the connected quintuple and sextuple components close to the basis-set limit, respectively.

Keywords: CCSDT $・$ CCSDTQ $・$ CCSDTQ5 $・$ CCSDTQ56 $・$ correlation-consistent $・$ basis set limit $\bullet$ basis set extrapolations

*E-Mail: amir.karton@uwa.edu.au 


\section{Introduction}

Coupled-cluster (CC) theory is one of the most cost-effective methods for approximating the exact solution for the nonrelativistic electronic Schrödinger equation. ${ }^{1,2}$ Coupled-cluster theory entails a hierarchy of approximations that can be systematically improved towards the exact quantum mechanical solution, providing a roadmap for the determination of highly accurate and reliable chemical properties. However, due to the inherently slow convergence of the correlation energy with respect to the one-particle basis set size, the only practical way to approximate the exact electronic energy near the one-particle basis-set limit is to use socalled post-CCSD(T) composite ab initio methods. ${ }^{3,4,5,6,7}$ In these methods successively higher cluster expansion terms (i.e., CCSD, (T), T-(T), (Q), Q-(Q), (5), etc.) are extrapolated (or calculated) near the basis-set limit using successively smaller basis sets. Indeed, the only reason that composite ab initio methods like W4 and HEAT-456QP can be carried out at a realistic computational cost for systems with multiple non-hydrogen atoms hinges on the faster basis-set convergence of the higher cluster expansion terms. ${ }^{3,8,9}$

A fairly large number of studies have been dedicated to studying the basis-set convergence of the $\operatorname{CCSD}$ and $\operatorname{CCSD}(\mathrm{T})$ methods near (or at) the infinite basis-set limit (for a number of $\begin{array}{lll}\text { representative } & \text { examples } & \text { seefs. }\end{array}$ $10,11,12,13,14,15,16,17,18,19,20,21,22,23,24,25,26,27,28,29,30,31,32,33,34)$. Fewer studies were dedicated to a systematic examination of basis set convergence of post-CCSD(T) excitations near the infinite basis-set limit. ${ }^{8,9,35,36,37,38,39,40,41,42}$ These works, however, were limited to considering small systems with 1-2 non-hydrogen atoms and/or did not consider post-CCSD(T) effects with sufficiently large basis sets and basis-set extrapolations. In addition, only a small subset of the considered molecules in these studies are characterized by a strong multireference character. 
In the present work we investigate the basis set convergence of post-CCSD(T) contributions to the total atomization energies (TAEs) for a wider and more diverse set of molecules with up to four non-hydrogen atoms. Furthermore, we focus entirely on systems that are dominated by moderate-to-severe nondynamical correlation effects, for which post-CCSD(T) effects are expected to be more pronounced. In particular, our set includes the following 21 systems: $\mathrm{BN}\left({ }^{1} \Sigma^{+}\right), \mathrm{C}_{2}\left({ }^{1} \Sigma^{+}\right), \mathrm{O}_{2}, \mathrm{FO}, \mathrm{P}_{2}, \mathrm{~S}_{2}, \mathrm{ClO}, \mathrm{N}_{2} \mathrm{O}, \mathrm{NO}_{2}, \mathrm{O}_{3}, \mathrm{FNO}, \mathrm{FO}_{2}, \mathrm{~F}_{2} \mathrm{O}, \mathrm{S}_{2} \mathrm{O}, \mathrm{S}_{3}$, $\mathrm{ClNO}, \mathrm{ClOO}, \mathrm{Cl}_{2} \mathrm{O}, \mathrm{N}_{2} \mathrm{C}_{2}, \mathrm{P}_{4}$, and $\mathrm{S}_{4}$. The chosen set is composed of five radicals $(\mathrm{FO} \cdot, \mathrm{ClO} \bullet$, $\mathrm{ONO} \cdot$, $\mathrm{FOO} \bullet$, and $\mathrm{ClOO} \bullet)$, two triplet systems $\left(\mathrm{O}_{2}\right.$ and $\left.\mathrm{S}_{2}\right)$, and 14 closed-shell species. This set evidently spans the gamut from systems dominated by moderate multireference character (e.g., $\mathrm{N}_{2} \mathrm{O}, \mathrm{NO}_{2}, \mathrm{~N}_{2} \mathrm{C}_{2}$, and $\mathrm{P}_{4}$ ) to systems dominated by severe nondynamical correlation (e.g., $\mathrm{C}_{2}, \mathrm{BN}, \mathrm{FO}_{2}, \mathrm{O}_{3}, \mathrm{ClOO}$, and $\mathrm{S}_{4}$ ). As such it constitutes an excellent set for analysis of basis set convergence of post-CCSD(T) contributions in multireference systems. For most of the diatomic molecules we were able to carry out CCSDT(Q)/cc-pV6Z, CCSDTQ/cc-pV5Z, CCSDTQ5(6)/cc-pVTZ, and CCSDTQ567/cc-pVDZ(3s2p) calculations. For most of the triatomic and tetra-atomic molecules we were able to carry out CCSDT(Q)/cc-pVQZ, CCSDTQ/cc-pVTZ， CCSDTQ(5)/cc-pVDZ(4s3p1d), CCSDTQ5/cc-pVDZ, and CCSDTQ56(7)/cc-pVDZ(3s2p) calculations. Here cc-pVDZ(4s3p1d) and cc-pVDZ(3s2p) denote truncated versions of the cc-pVDZ and cc-pVTZ basis sets, respectively (see Computational Methods). Using these basis-set limit values for a large and diverse set of challenging systems we attempt to answer questions such as:

* What is the magnitude of the various post-CCSD(T) contributions (namely, T-(T), (Q), Q-(Q), (5), 5-(5), (6), 6-(6), and 7) to the atomization energies of challenging systems?

* For each of the post-CCSD(T) contributions, what level of accuracy can we expect from a certain basis set or basis set extrapolation? 
* What are the most cost-effective approaches for obtaining each of the post-CCSD(T) contributions?

Finally, it should be pointed out that exploring basis-set convergence of higher-order correlation effects outside the equilibrium region is a topic of great interest, albeit beyond the scope of the present investigation. For previous works on this topic see for example refs. $43,44,45,46,47,48,49,50$.

\section{Computational Methods}

This work represents an extensive computational effort for obtaining basis-set limit values for post-CCSD(T) contributions for systems with $2-4$ non-hydrogen atoms. We note that many of the calculations reported here strained our computational resources to the absolute limit. For example, they involved 5-10 billion amplitudes and ran for over a month on 20 cores of dual Intel Xeon machines with 256-1024 GB of RAM (see supplementary material for further details).

All the geometries were optimized at the $\operatorname{CCSD}(\mathrm{T}) / \mathrm{cc}-\mathrm{pV}(\mathrm{Q}+\mathrm{d}) \mathrm{Z}$ level of theory and were taken from the W4-17 database $^{51}$ (the geometries are given in Table S1 of the supplementary material). This level of theory has been shown to yield geometries that are in close agreement $\operatorname{CCSD}(\mathrm{T})$ geometries near the complete basis-set (CBS) limit, e.g., with mean absolute deviations of $0.001 \AA$ from $\operatorname{CCSD}(\mathrm{T}) / \mathrm{cc}-\mathrm{pV}(6+\mathrm{d}) \mathrm{Z}$ geometries. ${ }^{52}$ All calculations were carried out using the MRCC program suite ${ }^{53,54}$ with the standard correlation-consistent basis sets of Dunning and co-workers. ${ }^{55,56,57}$ For the sake of brevity, the cc-pVnZ basis sets $(n=\mathrm{D}, \mathrm{T}, \mathrm{Q}, 5,6)$ are denoted by $\mathrm{V} n \mathrm{Z}$. In addition to the standard Dunning basis sets we use two non-standard basis sets. The first is a truncated version of the cc-pVDZ basis set in which the $d$ function has been omitted (denoted VDZ(3s2p)). The 
second is an extended version of the cc-pVDZ basis set in which the sp functions have been replaced with the sp functions from the cc-pVTZ basis set (denoted VDZ(4s3p1d)). All basis set extrapolations employ the $\mathrm{E}(L)=\mathrm{E}_{\infty}+\mathrm{A} / L^{\alpha}$ two-point extrapolation formula, unless otherwise indicated with $\alpha=3$ (where $L$ is the highest angular momentum represented in the basis sets for the non-hydrogen atoms). Basis set extrapolations using the $\mathrm{V} n \mathrm{Z}$ and $\mathrm{V}(n+1) \mathrm{Z}$ basis sets are denoted by $\mathrm{V}\{n, n+1\}$ Z. All calculations are nonrelativistic and are carried out within the frozen-core approximation, i.e., the $1 \mathrm{~s}$ orbitals for first-row atoms and the $1 \mathrm{~s}, 2 \mathrm{~s}$, and $2 \mathrm{p}$ orbitals for second-row atoms are constrained to be doubly occupied in all configurations.

\section{Results and Discussion}

In the present study we examine the basis set convergence of post-CCSD(T) contributions to molecular atomization energies near the one-particle basis set limit. We consider iterative and perturbative coupled cluster contributions up to connected septuples (CCSDTQ567) for a set of 21 first- and second- row molecules with up to four non-hydrogen atoms, spaning the gamut from systems dominated by moderate nondynamical correlation (e.g., $\mathrm{FO}, \mathrm{ClO}, \mathrm{NO}_{2}$, $\mathrm{S}_{2} \mathrm{O}, \mathrm{N}_{2} \mathrm{C}_{2}$, and $\mathrm{P}_{4}$ ) to systems dominated by strong nondynamical correlation (e.g., $\mathrm{BN}, \mathrm{C}_{2}$, $\mathrm{FO}_{2}, \mathrm{O}_{3}, \mathrm{ClOO}, \mathrm{S}_{3}$, and $\mathrm{S}_{4}$ ). For easy navigation between the subsections, Table 1 gives an overview of the $\mathrm{CC}$ excitations that are discussed in each of the subsections along with the abbreviations that are used. 
Table 1. Overview of the coupled-cluster contributions discussed in the present work.

\begin{tabular}{llll}
\hline Subsection & Name & Definition & Abbreviation \\
\hline 3.1 & Full-iterative connected triples & CCSDT-CCSD(T) & T-(T) \\
3.2 & Noniterative connected quadruples & CCSDT(Q)-CCSDT & $(\mathrm{Q})$ \\
3.3 & Full-iterative connected quadruples & CCSDTQ-CCSDT(Q) & Q-(Q) \\
3.4 & Connected quadruples as a whole & CCSDTQ-CCSDT & Q \\
3.5 & Noniterative quintuples & CCSDTQ(5)-CCSDTQ & $(5)$ \\
3.6 & Full-iterative connected quintuples & CCSDTQ5-CCSDTQ(5) & $5-(5)$ \\
3.7 & Connected quintuples as a whole & CCSDTQ5-CCSDTQ & 5 \\
3.8 & Noniterative sextuples & CCSDTQ5(6)-CCSDTQ5 & $(6)$ \\
3.8 & Full-iterative connected sextuples & CCSDTQ56-CCSDTQ5(6) & $6-(6)$ \\
3.8 & Connected sextuples as a whole & CCSDTQ56-CCSDT5 & 6 \\
3.9 & Noniterative septuples & CCSDTQ56(7)-CCSDTQ56 & $(7)$ \\
3.9 & Full-iterative connected septuples & CCSDTQ567-CCSDTQ56(7) & $7-(7)$ \\
3.9 & Connected septuples as a whole & CCSDTQ567-CCSDTQ56 & 7 \\
3.10 & Post-CCSD(T) as a whole & CCSDTQ567-CCSD(T) & N/A \\
\hline
\end{tabular}

3.1 Full-iterative connected triple excitations. For seven diatomic systems $\left(\mathrm{BN}, \mathrm{C}_{2}, \mathrm{O}_{2}, \mathrm{FO}\right.$, $\mathrm{P}_{2}, \mathrm{~S}_{2}$, and $\left.\mathrm{ClO}\right)$ we were able to obtain the $\mathrm{T}-(\mathrm{T})$ contribution to the TAEs at the complete basis-set limit from $\mathrm{V}\{5,6\} \mathrm{Z}$ extrapolations. These results, along with results for the VnZ basis sets $(n=\mathrm{D}-6)$ are given in Table 2 . Overall, the T-(T) component converges fairly smoothly to the CBS limit. For example, we obtain the following RMSDs relative to the $\mathrm{V}\{5,6\} Z$ reference values: 0.69 (VDZ), 0.22 (VTZ), 0.11 (VQZ), 0.06 (V5Z), and 0.04 (V6Z) kcal $\mathrm{mol}^{-1}$. Remarkably, the $\mathrm{V}\{\mathrm{D}, \mathrm{T}\} \mathrm{Z}$ extrapolation results in a similar overall performance to the V6Z basis set, with an RMSD of merely $0.04 \mathrm{kcal} \mathrm{mol}^{-1}$. Needless to say, this represents a remarkable saving in computer time and demonstrates the effectiveness of using basis set extrapolations for the $\mathrm{T}-(\mathrm{T})$ component. Extrapolating from the $\mathrm{V}\{\mathrm{T}, \mathrm{Q}\} \mathrm{Z}$ basis-set pair results in a slightly lower RMSD of $0.03 \mathrm{kcal} \mathrm{mol}^{-1}$ when an exponent of $\alpha=3$ is used. It was suggested that convergence in this basis set size regime is, however, slower than $\alpha=3$. In particular, ref. 37 suggested $\alpha=2.5$ as an effective exponent. Using $\alpha=2.5$ cuts the RMSD by over $50 \%$ to $0.013 \mathrm{kcal} \mathrm{mol}^{-1}$, and using an optimized exponent for our set of $\alpha=2.35$ results in an RMSD of merely $0.009 \mathrm{kcal} \mathrm{mol}^{-1}$. 
Table 2. Convergence of the full-iterative connected triples contribution, CCSDT-CCSD(T), to the total atomization energy for the set of seven diatomic molecules for which we were able to obtain basis-set limit values from $\mathrm{V}\{5,6\} \mathrm{Z}$ extrapolations. The $\mathrm{V}\{5,6\} \mathrm{Z}$ reference TAEs are listed in the last column, the tabulated values in the other columns are deviations relative to these basis-set limit values (in $\mathrm{kcal} \mathrm{mol}^{-1}$ ).

\begin{tabular}{lcccccccccc}
\hline $\begin{array}{l}\text { Basis set } \\
\alpha\end{array}$ & $\mathrm{VDZ}$ & $\mathrm{VTZ}$ & $\mathrm{VQZ}$ & $\mathrm{V} 5 Z$ & $\mathrm{~V} 6 Z$ & $\mathrm{~V}\{\mathrm{D}, \mathrm{T}\} \mathrm{Z}$ & $\mathrm{V}\{\mathrm{T}, \mathrm{Q}\} \mathrm{Z}$ & $\mathrm{V}\{\mathrm{T}, \mathrm{Q}\} \mathrm{Z}$ & $\mathrm{V}\{\mathrm{Q}, 5\} Z$ & $\mathrm{~V}\{5,6\} \mathrm{Z}$ \\
\hline $\mathrm{BN}$ & 0.695 & 0.229 & 0.122 & 0.064 & 0.037 & 0.033 & 0.043 & 0.010 & 0.004 & -2.676 \\
$\mathrm{C}_{2}$ & 1.048 & 0.379 & 0.185 & 0.097 & 0.056 & 0.097 & 0.043 & -0.016 & 0.004 & -2.291 \\
$\mathrm{O}_{2}$ & 0.507 & 0.139 & 0.077 & 0.040 & 0.023 & -0.015 & 0.031 & 0.012 & 0.002 & -0.528 \\
$\mathrm{FO}$ & 0.355 & 0.098 & 0.053 & 0.030 & 0.018 & -0.010 & 0.021 & 0.007 & 0.006 & 0.240 \\
$\mathrm{P}_{2}$ & 0.906 & 0.252 & 0.132 & 0.082 & 0.048 & -0.023 & 0.044 & 0.007 & 0.030 & -0.974 \\
$\mathrm{~S}_{2}$ & 0.652 & 0.200 & 0.100 & 0.063 & 0.036 & 0.010 & 0.026 & -0.004 & 0.024 & -0.508 \\
$\mathrm{ClO}$ & 0.301 & 0.092 & 0.048 & 0.030 & 0.018 & 0.005 & 0.015 & 0.002 & 0.012 & 0.031 \\
\hline $\mathrm{RMSD}^{a, b}$ & 0.687 & 0.220 & 0.112 & 0.063 & 0.036 & 0.040 & 0.034 & 0.009 & 0.016 & \\
$\mathrm{MAD}^{a, b}$ & 0.638 & 0.199 & 0.102 & 0.058 & 0.034 & 0.027 & 0.032 & 0.008 & 0.012 & \\
MSD $^{a, b}$ & 0.638 & 0.199 & 0.102 & 0.058 & 0.034 & 0.014 & 0.032 & 0.002 & 0.012 & \\
\hline
\end{tabular}

${ }^{a} \mathrm{RMSD}=$ root mean square deviation, MAD $=$ mean absolute deviation, MSD $=$ mean signed deviation, deviations are taken as [approx. value] - [ref. value].

${ }^{b}$ Error statistics with respect to the $\mathrm{V}\{5,6\} \mathrm{Z}$ reference values.

Since the V $\{\mathrm{T}, \mathrm{Q}\} \mathrm{Z}$ extrapolation with $\alpha=2.35$ results in a near-zero RMSD of 0.009 $\mathrm{kcal} \mathrm{mol}^{-1}$ relative to the $\mathrm{V}\{5,6\} \mathrm{Z}$ reference values, it is worthwhile evaluating the smaller basis sets against our best $\mathrm{V}\{\mathrm{T}, \mathrm{Q}\} \mathrm{Z}$ values, which we were able to obtain for the entire set of 21 molecules. These results are presented in Table 3 . We start by noting that for most molecules in our set the $\mathrm{T}-(\mathrm{T})$ contribution to the TAE is negative and large. The two exceptions for which the $\mathrm{T}-(\mathrm{T})$ contribution is positive are $\mathrm{FO}$ and $\mathrm{ClO}$ (namely, it is +0.25 and $+0.03 \mathrm{kcal} \mathrm{mol}^{-1}$, respectively). For 12 out of the 21 systems the $\mathrm{T}-(\mathrm{T})$ contribution approaches or exceeds the $-1 \mathrm{kcal} \mathrm{mol}^{-1}$ mark, and for four systems it even exceeds $-2 \mathrm{kcal}$ mol ${ }^{-1}$, namely: $\mathrm{C}_{2}(-2.31), \mathrm{BN}(-2.67), \mathrm{P}_{4}(-3.13)$, and $\mathrm{S}_{4}\left(-3.17 \mathrm{kcal} \mathrm{mol}^{-1}\right)$. 
Table 3. Convergence of the contribution of full-iterative connected triples contribution, CCSDT-CCSD(T), to the total atomization energy for the set of 21 molecules. The V $\{\mathrm{T}, \mathrm{Q}\} \mathrm{Z}$ reference TAEs (with $\alpha=2.35$ ) are listed in the last column, the tabulated values in the other columns are deviations relative to these basis-set limit values (in $\mathrm{kcal} \mathrm{mol}^{-1}$ ).

\begin{tabular}{cccccccc}
\hline Basis set & VDZ(3s2p) & VDZ & VDZ(4s3p1d) & VTZ & V\{D,T\}Z & V\{D,T\}Z & V\{T,Q\}Z \\
\hline$\alpha$ & & & & & 3.0 & 2.7 & 2.35 \\
\hline $\mathrm{BN}$ & -0.370 & 0.685 & 0.323 & 0.219 & 0.023 & -0.015 & -2.666 \\
$\mathrm{C}_{2}$ & 0.818 & 1.065 & 0.724 & 0.395 & 0.113 & 0.058 & -2.307 \\
$\mathrm{O}_{2}$ & 0.460 & 0.494 & 0.244 & 0.127 & -0.028 & -0.058 & -0.516 \\
$\mathrm{FO}$ & 0.410 & 0.348 & 0.198 & 0.091 & -0.017 & -0.038 & 0.247 \\
$\mathrm{P}_{2}$ & 1.048 & 0.899 & 0.811 & 0.246 & -0.029 & -0.083 & -0.967 \\
$\mathrm{~S}_{2}$ & 0.647 & 0.656 & 0.591 & 0.205 & 0.014 & -0.023 & -0.512 \\
$\mathrm{ClO}$ & 0.327 & 0.299 & 0.260 & 0.091 & 0.003 & -0.014 & 0.033 \\
$\mathrm{~N}_{2} \mathrm{O}$ & 0.949 & 1.085 & 0.666 & 0.369 & 0.068 & 0.009 & -1.571 \\
$\mathrm{NO}{ }_{2}$ & 1.093 & 1.103 & 0.683 & 0.385 & 0.082 & 0.024 & -0.963 \\
$\mathrm{O}_{3}$ & 1.148 & 1.327 & 0.777 & 0.468 & 0.107 & 0.037 & -1.462 \\
$\mathrm{FNO}_{\mathrm{FO}}$ & 1.169 & 1.065 & 0.631 & 0.362 & 0.066 & 0.009 & -0.731 \\
$\mathrm{FO}_{2}$ & 0.921 & 1.113 & 0.676 & 0.397 & 0.096 & 0.037 & -0.181 \\
$\mathrm{~F}_{2} \mathrm{O}$ & 0.701 & 0.768 & 0.418 & 0.213 & -0.021 & -0.067 & -0.581 \\
$\mathrm{~S}_{2} \mathrm{O}$ & 1.649 & 1.504 & 1.193 & 0.536 & 0.129 & 0.050 & -1.482 \\
$\mathrm{~S}_{3}$ & 2.039 & 1.714 & 1.569 & 0.617 & 0.156 & 0.066 & -1.529 \\
$\mathrm{ClNO}_{\mathrm{ClOO}}$ & 1.412 & 1.218 & 0.876 & 0.420 & 0.085 & 0.019 & -0.744 \\
$\mathrm{Cl}_{2} \mathrm{O}$ & 1.144 & 1.401 & 1.039 & 0.540 & 0.178 & 0.107 & -0.079 \\
$\mathrm{~N}_{2} \mathrm{C}_{2}$ & 1.032 & 0.936 & 0.744 & 0.314 & 0.051 & 0.001 & -0.975 \\
$\mathrm{P}_{4}$ & 3.577 & 1.394 & 0.896 & 0.452 & 0.056 & -0.021 & -1.956 \\
$\mathrm{~S}_{4}$ & 3.100 & 2.354 & 2.177 & 0.594 & -0.147 & -0.291 & -3.131 \\
\hline $\mathrm{RMSD}^{a, b}$ & 1.444 & 1.312 & 1.062 & 0.447 & 0.112 & 0.087 & \\
$\mathrm{MAD}^{a, b}$ & 1.210 & 1.161 & 0.868 & 0.388 & 0.085 & 0.057 & \\
$\mathrm{MSD}^{a, b}$ & 1.175 & 1.161 & 0.868 & 0.388 & 0.062 & -0.001 & \\
\hline
\end{tabular}

${ }^{a}$ See footnote $a$ to Table 2 .

${ }^{b}$ Error statistics with respect to the V $\{\mathrm{T}, \mathrm{Q}\} \mathrm{Z}$ reference values.

As expected, the double- $\zeta$ basis sets result in poor performance, with RMSDs of 1.44 (VDZ(3s2p)), 1.31 (VDZ), and $1.06(\mathrm{VDZ}(4 \mathrm{~s} 3 \mathrm{p} 1 \mathrm{~d})) \mathrm{kcal} \mathrm{mol}^{-1}$. The VTZ basis set still results in an unacceptably large RMSD of $0.45 \mathrm{kcal} \mathrm{mol}^{-1}$. This RMSD is reduced to 0.11 $\mathrm{kcal} \mathrm{mol}^{-1}$ for the $\mathrm{V}\{\mathrm{D}, \mathrm{T}\} \mathrm{Z}$ extrapolation with $\alpha=3.0$. Optimizing the exponent results in an RMSD of $0.09 \mathrm{kcal} \mathrm{mol}^{-1}$ with $\alpha=2.7$. The largest deviations of +0.17 and $-0.29 \mathrm{kcal} \mathrm{mol}^{-1}$ are obtained for $\mathrm{S}_{4}$ and $\mathrm{P}_{4}$, respectively. Exclusion of these two systems results in an RMSD of $0.05 \mathrm{kcal} \mathrm{mol}^{-1}$. 
3.2 Perturbative, noniterative connected quadruple excitations. For the seven diatomic molecules in our set we were able to obtain basis-set limit values from $\mathrm{V}\{5,6\} \mathrm{Z}$ extrapolations. Comparison of these $\mathrm{V}\{5,6\} Z$ CBS limits with $\mathrm{V}\{\mathrm{Q}, 5\} Z$ data reveals that the $\mathrm{V}\{\mathrm{Q}, 5\} \mathrm{Z}$ extrapolations are practically at the basis set limit, the largest deviations being $0.012 \mathrm{kcal} \mathrm{mol}^{-1}$ for $\mathrm{BN}$ and $\mathrm{C}_{2}$, followed by $0.005 \mathrm{kcal} \mathrm{mol}^{-1}$ for $\mathrm{FO}$ and $\mathrm{ClO}$. Over the set of seven diatomics, the $\mathrm{V}\{\mathrm{Q}, 5\} \mathrm{Z}$ extrapolation results in an RMSD of $0.007 \mathrm{kcal} \mathrm{mol}^{-1}$ and a MAD of $0.002 \mathrm{kcal} \mathrm{mol}^{-1}$.

Even basis-set limit results extrapolated from $\mathrm{V}\{\mathrm{T}, \mathrm{Q}\} \mathrm{Z}$ fair well with the $\mathrm{V}\{5,6\} \mathrm{Z}$ results, with an RMSD and MAD of 0.014 and $0.004 \mathrm{kcal} \mathrm{mol}^{-1}$, respectively. The largest deviations being $0.017,0.018$, and $0.022 \mathrm{kcal} \mathrm{mol}^{-1}$ for $\mathrm{P}_{2}, \mathrm{BN}$, and $\mathrm{C}_{2}$, respectively. This suggests that the $\mathrm{V}\{\mathrm{T}, \mathrm{Q}\} \mathrm{Z}$ results, which we were able to obtain for all the 21 systems, could be used as reference values for evaluating the performance of the smaller basis sets. These results are presented in Table 4. 
Table 4. Convergence of the perturbative, noniterative connected quadruples contribution, $\operatorname{CCSDT}(\mathrm{Q})-\mathrm{CCSDT}$, to the total atomization energy (in $\mathrm{kcal} \mathrm{mol}^{-1}$ ). The last five columns list TAEs, the tabulated values in the other columns are deviations relative to basis-set limit values from $\mathrm{V}\{\mathrm{T}, \mathrm{Q}\} \mathrm{Z}$ extrapolations (in $\mathrm{kcal} \mathrm{mol}^{-1}$ ).

\begin{tabular}{|c|c|c|c|c|c|c|c|c|c|c|c|c|c|}
\hline $\begin{array}{c}\text { Basis set } \\
\alpha\end{array}$ & VDZ & $1.25 \times \mathrm{VDZ}$ & VTZ & $1.1 \times \mathrm{VTZ}$ & VQZ & $\begin{array}{c}\mathrm{V}\{\mathrm{D}, \mathrm{T}\} \mathrm{Z} \\
3.0\end{array}$ & $\begin{array}{c}\mathrm{V}\{\mathrm{D}, \mathrm{T}\} \mathrm{Z} \\
2.4\end{array}$ & $\begin{array}{c}\mathrm{V}\{\mathrm{T}(4 \mathrm{~s} 3 \mathrm{p} 1 \mathrm{~d}), \mathrm{T}\} \mathrm{Z} \\
2.3\end{array}$ & $\begin{array}{c}\mathrm{V}\{\mathrm{T}, \mathrm{Q}\} \mathrm{Z} \\
3.0\end{array}$ & V5Z & V6Z & $\begin{array}{c}\mathrm{V}\{\mathrm{Q}, 5\} \mathrm{Z} \\
3.0\end{array}$ & $\begin{array}{c}\mathrm{V}\{5,6\} \mathrm{Z} \\
3.0\end{array}$ \\
\hline $\mathrm{BN}$ & -0.818 & -0.202 & -0.255 & 0.048 & -0.108 & -0.018 & 0.084 & -0.024 & 3.281 & 3.223 & 3.240 & 3.275 & 3.263 \\
\hline $\mathrm{C}_{2}$ & -0.793 & -0.129 & -0.228 & 0.094 & -0.096 & 0.010 & 0.111 & 0.041 & 3.448 & 3.393 & 3.407 & 3.437 & 3.426 \\
\hline $\mathrm{O}_{2}$ & -0.082 & 0.199 & -0.111 & -0.001 & -0.047 & -0.123 & -0.128 & -0.032 & 1.204 & 1.179 & 1.187 & 1.202 & 1.198 \\
\hline FO & -0.097 & 0.065 & -0.102 & -0.037 & -0.043 & -0.104 & -0.105 & -0.027 & 0.747 & 0.725 & 0.733 & 0.748 & 0.743 \\
\hline $\mathrm{P}_{2}$ & -0.626 & -0.366 & -0.235 & -0.092 & -0.099 & -0.071 & 0.000 & 0.003 & 1.666 & 1.608 & 1.625 & 1.651 & 1.649 \\
\hline $\mathrm{S}_{2}$ & -0.475 & -0.350 & -0.179 & -0.099 & -0.075 & -0.054 & 0.000 & 0.016 & 0.975 & 0.939 & 0.956 & 0.980 & 0.980 \\
\hline $\mathrm{ClO}$ & -0.324 & -0.210 & -0.154 & -0.092 & -0.065 & -0.083 & -0.053 & -0.019 & 0.780 & 0.756 & 0.772 & 0.799 & 0.794 \\
\hline $\mathrm{N}_{2} \mathrm{O}$ & -0.267 & 0.284 & -0.209 & 0.017 & -0.088 & -0.184 & -0.174 & -0.075 & 2.468 & & & & \\
\hline $\mathrm{NO}_{2}$ & -0.308 & 0.206 & -0.238 & -0.025 & -0.100 & -0.208 & -0.196 & -0.075 & 2.361 & & & & \\
\hline $\mathrm{O}_{3}$ & -0.663 & 0.370 & -0.412 & 0.026 & -0.174 & -0.306 & -0.261 & -0.132 & 4.795 & & & & \\
\hline FNO & -0.216 & 0.207 & -0.196 & -0.025 & -0.083 & -0.188 & -0.185 & -0.066 & 1.910 & & & & \\
\hline $\mathrm{FO}_{2}$ & -0.605 & 0.146 & -0.370 & -0.046 & -0.156 & -0.271 & -0.229 & -0.138 & 3.610 & & & & \\
\hline $\mathrm{F}_{2} \mathrm{O}$ & -0.186 & 0.185 & -0.198 & -0.052 & -0.084 & -0.204 & -0.206 & -0.060 & 1.667 & & & & \\
\hline $\mathrm{S}_{2} \mathrm{O}$ & -0.604 & -0.140 & -0.270 & -0.050 & -0.114 & -0.129 & -0.069 & 0.011 & 2.463 & & & & \\
\hline $\mathrm{S}_{3}$ & -1.146 & -0.707 & -0.410 & -0.160 & -0.173 & -0.100 & 0.033 & 0.050 & 2.901 & & & & \\
\hline CINO & -0.570 & -0.124 & -0.271 & -0.062 & -0.114 & -0.145 & -0.090 & -0.037 & 2.354 & & & & \\
\hline $\mathrm{ClOO}$ & -0.968 & -0.247 & -0.448 & -0.107 & -0.189 & -0.229 & -0.135 & -0.069 & 3.852 & & & & \\
\hline $\mathrm{Cl}_{2} \mathrm{O}$ & -0.444 & -0.201 & -0.209 & -0.089 & -0.088 & -0.111 & -0.068 & 0.004 & 1.417 & & & & \\
\hline $\mathrm{N}_{2} \mathrm{C}_{2}$ & -0.496 & 0.045 & -0.245 & -0.004 & -0.103 & -0.140 & -0.094 & -0.062 & 2.657 & & & & \\
\hline $\mathrm{P}_{4}$ & -1.381 & -0.937 & -0.497 & -0.231 & -0.210 & -0.125 & 0.035 & 0.030 & 3.155 & & & & \\
\hline $\mathrm{S}_{4}$ & -2.013 & -1.060 & -0.688 & -0.175 & -0.290 & -0.131 & 0.108 & 0.136 & 5.823 & & & & \\
\hline $\operatorname{RMSD}^{a, b}$ & 0.769 & 0.402 & 0.314 & 0.048 & 0.133 & 0.158 & 0.133 & 0.066 & & & & & \\
\hline $\mathrm{MAD}^{a, b}$ & 0.623 & 0.304 & 0.282 & 0.094 & 0.119 & 0.140 & 0.113 & 0.053 & & & & & \\
\hline $\operatorname{MSD}^{a, b}$ & -0.623 & -0.141 & -0.282 & -0.001 & -0.119 & -0.139 & -0.077 & -0.025 & & & & & \\
\hline
\end{tabular}

${ }^{a}$ See footnote $a$ to Table 2 .

${ }^{b}$ Error statistics with respect to the $\mathrm{V}\{\mathrm{T}, \mathrm{Q}\} \mathrm{Z}$ reference values for the 21 systems above.

For all the molecules in our set the $(\mathrm{Q}) / \mathrm{V}\{\mathrm{T}, \mathrm{Q}\} \mathrm{Z}$ contribution to the TAE is positive and large. Namely, it ranges between 1-6 kcal mol${ }^{-1}$. For seven molecules this contribution exceeds the $3 \mathrm{kcal} \mathrm{mol}^{-1}$ mark, namely: $\mathrm{P}_{4}$ (3.15), $\mathrm{BN}$ (3.28), $\mathrm{C}_{2}(3.45), \mathrm{FO}_{2}(3.61), \mathrm{ClOO}$ (3.85), $\mathrm{O}_{3}(4.79)$, and $\mathrm{S}_{4}\left(5.82 \mathrm{kcal} \mathrm{mol}^{-1}\right)$.

It has been previously shown that the VDZ basis set overshoots the (Q) contribution in highly polar systems (such as $\mathrm{HF}$ and $\mathrm{H}_{2} \mathrm{O}$ ) and severely undershoots the (Q) contribution in second-row molecules. ${ }^{37}$ For the set of molecules in Table 4 the VDZ basis set systematically underestimates the $\mathrm{V}\{\mathrm{T}, \mathrm{Q}\} \mathrm{Z}$ results. For the first-row systems underestimations ranging between $0.08\left(\mathrm{O}_{2}\right)$ and $0.82(\mathrm{BN}) \mathrm{kcal} \mathrm{mol}^{-1}$ are obtained. Whilst for systems comprising of solely second-row systems higher underestimations are obtained, namely they range between $0.48\left(\mathrm{~S}_{2}\right)$ and $2.01\left(\mathrm{~S}_{4}\right) \mathrm{kcal} \mathrm{mol}^{-1}$. Overall, for the set of 21 systems in Table 4 an RMSD of $0.77 \mathrm{kcal} \mathrm{mol}^{-1}$ is obtained relative to the $\mathrm{V}\{\mathrm{T}, \mathrm{Q}\} \mathrm{Z}$ results. 
Scaling the (Q)/VDZ component by 1.1 , as is done in the W4lite composite method, ${ }^{8}$ reduces the RMSD to $0.59 \mathrm{kcal} \mathrm{mol}^{-1}$. Whilst an optimal scaling factor of 1.25 results in a much lower RMSD of $0.40 \mathrm{kcal} \mathrm{mol}^{-1}$. Nevertheless, underestimations of about $1 \mathrm{kcal} \mathrm{mol}^{-1}$ are still obtained for $\mathrm{P}_{4}(-0.94)$ and $\mathrm{S}_{4}(-1.06) \mathrm{kcal} \mathrm{mol}^{-1}$. Thus, the VDZ basis set is not recommended for highly accurate applications involving second-row and/or highly polar species.

The (Q)/VTZ results fair better with an RMSD of $0.31 \mathrm{kcal} \mathrm{mol}^{-1}$ and largest underestimations of $0.41\left(\mathrm{O}_{3}\right.$ and $\left.\mathrm{S}_{3}\right), 0.50\left(\mathrm{P}_{4}\right)$, and $0.69\left(\mathrm{~S}_{4}\right)$. Two ways of improving the performance of the $(\mathrm{Q}) / \mathrm{VTZ}$ results with no increase in computational cost are scaling the (Q)/VTZ results by 1.1 as used in the $\mathrm{W} 4$ composite method ${ }^{8}$ or extrapolating from the $\mathrm{V}\{\mathrm{D}, \mathrm{T}\} \mathrm{Z}$ basis set pair. Scaling by 1.1 results in significantly better performance with an RMSD of $0.09 \mathrm{kcal} \mathrm{mol}^{-1}$, compared to an RMSD of $0.16 \mathrm{kcal} \mathrm{mol}^{-1}$ for the $\mathrm{V}\{\mathrm{D}, \mathrm{T}\} \mathrm{Z}$ extrapolation with $\alpha=3$. We note that using an optimal extrapolation exponent (of 2.4 instead of 3) in the $(\mathrm{Q}) / \mathrm{V}\{\mathrm{D}, \mathrm{T}\} \mathrm{Z}$ extrapolation still results in inferior performance to scaling with an RMSD of $0.13 \mathrm{kcal} \mathrm{mol}^{-1}$. Furthermore, inspection of the largest deviations reveals that scaling is a better approach. In particular, the $(\mathrm{Q}) / \mathrm{V}\{\mathrm{D}, \mathrm{T}\} \mathrm{Z}$ extrapolation (with $\alpha=2.4$ ) results in 11 deviations larger than $0.1 \mathrm{kcal} \mathrm{mol}^{-1}$ (in absolute value), whereas the $1.1 \times(\mathrm{Q}) / \mathrm{VTZ}$ approach results in only four deviations larger than $0.1 \mathrm{kcal} \mathrm{mol}^{-1}$.

As pointed out previously, ${ }^{37,8,39}$ the poor performance of the $\mathrm{V}\{\mathrm{D}, \mathrm{T}\} \mathrm{Z}$ extrapolations is due to the anemic character of the cc-pVDZ basis set. One way to overcome this problem, which has not been considered in the past, is to extrapolate using the cc-pVTZ basis set in conjunction with an spd quality basis set in which the $\mathrm{s}$ and $\mathrm{p}$ shells are more saturated. Indeed, extrapolating the (Q) component from the VDZ(4s3p1d) and VTZ basis sets results in an RMSD of merely $0.07 \mathrm{kcal} \mathrm{mol}^{-1}$ and only three deviations larger than $0.1 \mathrm{kcal} \mathrm{mol}^{-1}$. Namely, $-0.14\left(\mathrm{FO}_{2}\right),-0.13\left(\mathrm{O}_{3}\right)$, and $+0.13\left(\mathrm{~S}_{4}\right) \mathrm{kcal} \mathrm{mol}^{-1}$. A near-zero MSD of $-0.03 \mathrm{kcal}$ 
$\mathrm{mol}^{-1}$ suggests that this extrapolation is free of systematic bias. This approach has the same computational cost as the $1.1 \times(\mathrm{Q}) / \mathrm{VTZ}$ and $(\mathrm{Q}) / \mathrm{V}\{\mathrm{D}, \mathrm{T}\} \mathrm{Z}$ levels of theory, but results is better performance and is therefore recommended for the $(\mathrm{Q})$ component.

3.3 Full-iterative connected quadruple excitations. For three systems $\left(\mathrm{BN}, \mathrm{C}_{2}\right.$, and $\left.\mathrm{P}_{2}\right)$ we were able to obtain the $\mathrm{Q}-(\mathrm{Q})$ contribution to the TAEs at the complete basis-set limit from $\mathrm{V}\{\mathrm{Q}, 5\} Z$ extrapolations. The $\mathrm{V}\{\mathrm{T}, \mathrm{Q}\} \mathrm{Z}$ extrapolation essentially reproduces these basis-set limit values spot-on with all deviations being smaller than $0.005 \mathrm{kcal} \mathrm{mol}^{-1}$. We can therefore use the $V\{T, Q\} Z$ values, which we have for the seven diatomics, for evaluating the performance of the smaller basis sets. These results are presented in Table 5. The VTZ basis set results in a respectable RMSD of $0.037 \mathrm{kcal} \mathrm{mol}^{-1}$ and a largest deviation of $0.046 \mathrm{kcal}$ $\mathrm{mol}^{-1}$ obtained for $\mathrm{C}_{2}$. Extrapolating from the VDZ and VTZ basis sets with an exponent of $\alpha$ $=3$ significantly improves the performance and results in an RMSD of $0.023 \mathrm{kcal} \mathrm{mol}^{-1}$ and a largest deviation of $0.030 \mathrm{kcal} \mathrm{mol}^{-1}$ obtained for $\mathrm{C}_{2}$. Nevertheless, calculating the CCSDTQ energy in conjunction with the VTZ is prohibitively expensive for molecules with more than two non-hydrogen atoms. The largest basis set with which we were able to calculate the Q(Q) corrections for all the 21 systems is the VDZ(4s3p1d) basis set. Relative to the V $\{\mathrm{T}, \mathrm{Q}\} \mathrm{Z}$ CBS values, this basis set attains an RMSD of $0.051 \mathrm{kcal} \mathrm{mol}^{-1}$ and a largest deviation of $0.072 \mathrm{kcal} \mathrm{mol}^{-1}$ obtained for $\mathrm{P}_{2}$ (Table 5). Scaling the $\mathrm{VDZ}(4 \mathrm{~s} 3 \mathrm{p} 1 \mathrm{~d})$ results by a scaling factor of 1.05 slightly improves the performance and reduces the RMSD to $0.043 \mathrm{kcal} \mathrm{mol}^{-1}$. We note, however, that this does not represent an improvement over scaling the VDZ results with a scaling factor of 1.1, which results in essentially the same error statistics (Table 5). Scaling the VDZ results by 1.1 has been found to be an efficient and cost-effective approach for obtaining the $\mathrm{Q}-(\mathrm{Q})$ correction and is used in the W4 composite method. ${ }^{37,8}$ 
Table 5. Convergence of the full-iterative connected quadruples contribution, CCSDTQ$\operatorname{CCSDT}(\mathrm{Q})$, to the total atomization energy for the set of seven diatomic molecules for which we were able to obtain basis-set limit values from $\mathrm{V}\{\mathrm{T}, \mathrm{Q}\} \mathrm{Z}$ extrapolations. The last two columns list TAEs, the tabulated values in the other columns are deviations relative to basisset limit values from $\mathrm{V}\{\mathrm{T}, \mathrm{Q}\} \mathrm{Z}$ extrapolations (in $\mathrm{kcal} \mathrm{mol}^{-1}$ ).

\begin{tabular}{|c|c|c|c|c|c|c|c|c|c|c|}
\hline & $\operatorname{VDZ}(3 \mathrm{~s} 2 \mathrm{p})$ & VDZ & $1.1 \times \mathrm{VDZ}$ & $\operatorname{VDZ}(4 \mathrm{~s} 3 \mathrm{p} 1 \mathrm{~d})$ & $1.05 \times \operatorname{VDZ}(4 \mathrm{~s} 3 \mathrm{p} 1 \mathrm{~d})$ & VTZ & VQZ & $\mathrm{V}\{\mathrm{D}, \mathrm{T}\} \mathrm{Z}$ & $\mathrm{V}\{\mathrm{T}, \mathrm{Q}\} \mathrm{Z}$ & $\mathrm{V}\{\mathrm{Q}, 5\} \mathrm{Z}$ \\
\hline $\mathrm{BN}$ & 0.391 & 0.115 & 0.006 & 0.016 & -0.043 & 0.046 & 0.019 & 0.017 & -1.201 & -1.200 \\
\hline $\mathrm{C}_{2}$ & -0.147 & 0.080 & -0.027 & 0.062 & 0.007 & 0.045 & 0.019 & 0.030 & -1.147 & -1.151 \\
\hline $\mathrm{O}_{2}$ & 0.071 & 0.034 & 0.021 & 0.051 & 0.045 & 0.031 & 0.013 & 0.029 & -0.159 & \\
\hline $\mathrm{FO}$ & 0.082 & 0.057 & 0.042 & 0.036 & 0.028 & 0.022 & 0.009 & 0.008 & -0.207 & \\
\hline $\mathrm{P}_{2}$ & 0.039 & 0.078 & 0.067 & 0.072 & 0.066 & 0.040 & 0.017 & 0.024 & -0.185 & -0.189 \\
\hline $\mathrm{S}_{2}$ & 0.124 & 0.038 & 0.033 & 0.035 & 0.033 & 0.028 & 0.012 & 0.023 & -0.088 & \\
\hline $\mathrm{ClO}$ & 0.128 & 0.080 & 0.073 & 0.060 & 0.056 & 0.039 & 0.017 & 0.022 & -0.149 & \\
\hline $\operatorname{RMSD}^{a, b}$ & 0.177 & 0.074 & 0.045 & 0.051 & 0.043 & 0.037 & 0.015 & 0.023 & & \\
\hline $\mathrm{MAD}^{a, b}$ & 0.140 & 0.069 & 0.039 & 0.047 & 0.040 & 0.036 & 0.015 & 0.022 & & \\
\hline $\operatorname{MSD}^{a, b}$ & 0.098 & 0.069 & 0.031 & 0.047 & 0.027 & 0.036 & 0.015 & 0.022 & & \\
\hline
\end{tabular}

${ }^{a}$ See footnote $a$ to Table 2 .

${ }^{b}$ Error statistics with respect to the $\mathrm{V}\{\mathrm{T}, \mathrm{Q}\} \mathrm{Z}$ reference values.

Table 6 gives the Q-(Q) contribution to the TAEs for the 21 systems in our set calculated with basis sets of up to VDZ(4s3p1d) and error statistics for the VDZ(3s2p) and VDZ with respect to the best reference values (i.e., $1.05 \times \mathrm{VDZ}(4 \mathrm{~s} 3 \mathrm{p} 1 \mathrm{~d}))$. Let us begin by noting that the magnitude of the $\mathrm{Q}-(\mathrm{Q})$ contribution to the TAE spans a wide range from $0.06\left(\mathrm{~S}_{2}\right)$ to $-1.25(\mathrm{BN}) \mathrm{kcal} \mathrm{mol}^{-1}$. Perhaps it is not surprising that the largest $\mathrm{Q}-(\mathrm{Q})$ contributions are obtained for the strongly multireference systems: $\mathrm{ClOO}(-0.62), \mathrm{FO}_{2}(-$ $0.68), \mathrm{S}_{4}(-0.79), \mathrm{O}_{3}(-0.96), \mathrm{C}_{2}(-1.14)$, and $\mathrm{BN}\left(-1.25 \mathrm{kcal} \mathrm{mol}^{-1}\right)$.

The VDZ(3s2p) basis set results in a fairly large RMSD of $0.155 \mathrm{kcal} \mathrm{mol}^{-1}$. This is in part due to the very large deviations of 0.43 and $0.37 \mathrm{kcal} \mathrm{mol}^{-1}$ obtained for $\mathrm{BN}$ and $\mathrm{S}_{4}$. Eliminating these two systems results in an RMSD of $0.097 \mathrm{kcal} \mathrm{mol}^{-1}$. Table 6 also shows that scaling the VDZ results by a scaling factor of 1.1 results in an RMSD of merely 0.027 $\mathrm{kcal} \mathrm{mol}^{-1}$ for the set of 21 systems. 
Table 6. Convergence of the full-iterative connected quadruples contribution, CCSDTQ$\operatorname{CCSDT}(\mathrm{Q})$, to the total atomization energy for the set of 21 molecules for which we were able to obtain this contribution with the $1.05 \times \mathrm{VDZ}(4 \mathrm{~s} 3 \mathrm{p} 1 \mathrm{~d})$ basis set. The last two columns list TAEs, the tabulated values in the other columns are deviations relative to $1.05 \times \operatorname{VDZ}(4 \mathrm{~s} 3 \mathrm{p} 1 \mathrm{~d})$ values (in $\left.\mathrm{kcal} \mathrm{mol}^{-1}\right)$.

\begin{tabular}{|c|c|c|c|c|c|c|}
\hline & $\operatorname{VDZ}(3 \mathrm{~s} 2 \mathrm{p})$ & $1.05 \times \operatorname{VDZ}(3 \mathrm{~s} 2 \mathrm{p})$ & VDZ & $1.1 \times \mathrm{VDZ}$ & $1.05 \times \operatorname{VDZ}(4 \mathrm{~s} 3 \mathrm{p} 1 \mathrm{~d})$ & $\mathrm{V}\{\mathrm{D}, \mathrm{T}\} \mathrm{Z}$ \\
\hline $\mathrm{BN}$ & 0.434 & 0.394 & 0.158 & 0.049 & -1.245 & -1.185 \\
\hline $\mathrm{C}_{2}$ & -0.154 & -0.219 & 0.072 & -0.035 & -1.139 & -1.117 \\
\hline $\mathrm{O}_{2}$ & 0.026 & 0.022 & -0.011 & -0.024 & -0.114 & -0.130 \\
\hline FO & 0.055 & 0.048 & 0.030 & 0.015 & -0.179 & -0.199 \\
\hline $\mathrm{P}_{2}$ & -0.027 & -0.035 & 0.012 & 0.001 & -0.119 & -0.162 \\
\hline $\mathrm{S}_{2}$ & 0.092 & 0.094 & 0.006 & 0.001 & -0.055 & -0.065 \\
\hline $\mathrm{ClO}$ & 0.072 & 0.071 & 0.025 & 0.018 & -0.094 & -0.127 \\
\hline $\mathrm{N}_{2} \mathrm{O}$ & -0.011 & -0.034 & -0.002 & -0.048 & -0.453 & \\
\hline $\mathrm{NO}_{2}$ & 0.033 & 0.015 & 0.013 & -0.027 & -0.404 & \\
\hline $\mathrm{O}_{3}$ & 0.101 & 0.059 & 0.034 & -0.058 & -0.955 & -1.002 \\
\hline FNO & 0.022 & 0.007 & 0.009 & -0.024 & -0.332 & \\
\hline $\mathrm{FO}_{2}$ & 0.122 & 0.094 & 0.072 & 0.011 & -0.683 & \\
\hline $\mathrm{F}_{2} \mathrm{O}$ & 0.031 & 0.022 & 0.000 & -0.021 & -0.212 & -0.228 \\
\hline $\mathrm{S}_{2} \mathrm{O}$ & -0.017 & -0.038 & 0.020 & -0.017 & -0.393 & \\
\hline $\mathrm{S}_{3}$ & 0.143 & 0.134 & 0.028 & -0.001 & -0.316 & -0.348 \\
\hline $\mathrm{CINO}$ & 0.057 & 0.044 & 0.016 & -0.015 & -0.320 & \\
\hline $\mathrm{ClOO}$ & 0.139 & 0.115 & 0.052 & -0.005 & -0.615 & \\
\hline $\mathrm{Cl}_{2} \mathrm{O}$ & 0.074 & 0.071 & 0.001 & -0.014 & -0.152 & -0.175 \\
\hline $\mathrm{N}_{2} \mathrm{C}_{2}$ & 0.026 & 0.009 & -0.016 & -0.052 & -0.349 & \\
\hline $\mathrm{P}_{4}$ & 0.247 & 0.242 & 0.028 & -0.005 & -0.352 & \\
\hline $\mathrm{S}_{4}$ & 0.366 & 0.345 & 0.062 & -0.011 & -0.788 & \\
\hline $\mathrm{RMSD}^{a, b}$ & 0.155 & 0.147 & 0.047 & 0.027 & & \\
\hline $\operatorname{MAD}^{a, b}$ & 0.107 & 0.100 & 0.032 & 0.021 & & \\
\hline $\mathrm{MSD}^{a, b}$ & 0.087 & 0.069 & 0.029 & -0.012 & & \\
\hline
\end{tabular}

${ }^{a}$ See footnote $a$ to Table 2 .

${ }^{b}$ Error statistics with respect to the $1.05 \times \mathrm{VDZ}(4 \mathrm{~s} 3 \mathrm{p} 1 \mathrm{~d})$ reference values for the 21 systems.

3.4 Connected quadruple excitations as a whole. For three systems we were able to extrapolate the CCSDTQ-CCSDT contribution to the TAE from the cc-pVQZ and cc-pV5Z basis sets. The differences between these basis-set limit values and cc-pV $\{\mathrm{T}, \mathrm{Q}\} \mathrm{Z}$ results are $0.005(\mathrm{BN}), 0.015\left(\mathrm{C}_{2}\right)$, and $0.019\left(\mathrm{P}_{2}\right) \mathrm{kcal} \mathrm{mol}^{-1}$. We will therefore use the $\mathrm{V}\{\mathrm{T}, \mathrm{Q}\} \mathrm{Z}$ results to evaluate the performance of more cost-effective approaches. These results are given in Table 7. The double- $\zeta$ type basis sets result in very large RMSDs of 0.86 (VDZ(3s $2 p)$ ), 0.47 (VDZ), 0.44 (VDZ(4s3p1d)) $\mathrm{kcal} \mathrm{mol}^{-1}$. Even the VTZ basis set leads to an appreciable RMSD of $0.15 \mathrm{kcal} \mathrm{mol}^{-1}$. Inspection of the MSDs reveals that the VDZ, VDZ(4s3p1d), and VTZ basis sets systematically underestimate the $\mathrm{V}\{\mathrm{T}, \mathrm{Q}\} \mathrm{Z}$ results (Table 7). Thus, scaling 
significantly improves the performance, and leads to RMSDs of $0.20(1.4 \times \mathrm{VDZ}), 0.15$ $(1.4 \times \mathrm{VDZ}(4 \mathrm{~s} 3 \mathrm{p} 1 \mathrm{~d}))$, and $0.05(1.1 \times \mathrm{VTZ}) \mathrm{kcal} \mathrm{mol}^{-1}$.

Table 7. Convergence of the connected quadruples contribution, CCSDTQ-CCSDT, to the total atomization energy for the set of seven diatomic molecules for which we were able to obtain basis-set limit values from $\mathrm{V}\{\mathrm{T}, \mathrm{Q}\} Z$ extrapolations. The last two columns list TAEs, the tabulated values in the other columns are deviations relative to basis-set limit values from $\mathrm{V}\{\mathrm{T}, \mathrm{Q}\} \mathrm{Z}$ extrapolations (in $\mathrm{kcal} \mathrm{mol}^{-1}$ ).

\begin{tabular}{|c|c|c|c|c|c|c|c|c|c|c|c|c|}
\hline$\alpha$ & $\begin{array}{c}\text { VDZ } \\
(3 s 2 p)\end{array}$ & VDZ & $1.4 \times \mathrm{VDZ}$ & $\begin{array}{c}\text { VDZ } \\
(4 s 3 p 1 d)\end{array}$ & $\begin{array}{c}1.4 \times V D Z \\
(4 \mathrm{~s} 3 \mathrm{p} 1 \mathrm{~d})\end{array}$ & VTZ & $1.1 \times \mathrm{VTZ}$ & VQZ & $\mathrm{V}\{\mathrm{D}, \mathrm{T}\} \mathrm{Z}$ & $\mathrm{V}\{\mathrm{D}(4 \mathrm{~s} 3 \mathrm{p} 1 \mathrm{~d}), \mathrm{T}\} \mathrm{Z}$ & $\mathrm{V}\{\mathrm{T}, \mathrm{Q}\} \mathrm{Z}$ & $\mathrm{V}\{\mathrm{Q}, 5\} Z$ \\
\hline $\mathrm{BN}$ & -1.545 & -0.703 & -0.153 & -0.595 & -0.001 & -0.209 & -0.022 & -0.088 & 0.003 & -0.003 & 2.079 & 2.075 \\
\hline $\mathrm{C}_{2}$ & -1.510 & -0.713 & -0.078 & -0.580 & 0.108 & -0.184 & 0.028 & -0.077 & 0.044 & 0.029 & 2.301 & 2.286 \\
\hline $\mathrm{O}_{2}$ & 0.039 & -0.048 & 0.351 & -0.181 & 0.164 & -0.080 & 0.017 & -0.034 & -0.094 & -0.026 & 1.045 & \\
\hline FO & -0.106 & -0.040 & 0.160 & -0.181 & -0.037 & -0.079 & -0.033 & -0.034 & -0.097 & -0.025 & 0.540 & \\
\hline $\mathrm{P}_{2}$ & -0.392 & -0.548 & -0.175 & -0.531 & -0.152 & -0.196 & -0.067 & -0.083 & -0.044 & -0.016 & 1.481 & 1.462 \\
\hline $\mathrm{S}_{2}$ & -0.388 & -0.437 & -0.257 & -0.444 & -0.266 & -0.151 & -0.078 & -0.064 & -0.029 & 0.005 & 0.887 & \\
\hline $\mathrm{ClO}$ & -0.386 & -0.244 & -0.089 & -0.303 & -0.172 & -0.115 & -0.063 & -0.049 & -0.060 & -0.014 & 0.630 & \\
\hline $\mathrm{RMSD}^{a, b}$ & 0.857 & 0.472 & 0.201 & 0.435 & 0.153 & 0.153 & 0.050 & 0.065 & 0.061 & 0.019 & & \\
\hline MAD $^{a, b}$ & 0.624 & 0.390 & 0.180 & 0.402 & 0.129 & 0.145 & 0.044 & 0.061 & 0.053 & 0.017 & & \\
\hline $\operatorname{MSD}^{a, b}$ & -0.613 & -0.390 & -0.034 & -0.402 & -0.051 & -0.145 & -0.031 & -0.061 & -0.039 & -0.007 & & \\
\hline
\end{tabular}

${ }^{a}$ See footnote $a$ to Table 2 .

${ }^{b}$ Error statistics with respect to the $\mathrm{V}\{\mathrm{T}, \mathrm{Q}\} \mathrm{Z}$ reference values.

Extrapolating the connected quadruple excitations from the VDZ and VTZ basis sets with an exponent of $\alpha=3.0$ results in an RMSD of $0.06 \mathrm{kcal} \mathrm{mol}^{-1}$, which is higher than that obtained for scaling the VTZ results by a scaling factor of $1.1\left(0.05 \mathrm{kcal} \mathrm{mol}^{-1}\right.$, Table 7$)$. We note that optimizing the extrapolation exponent results in essentially the same exponent and RMSD. This indicates that the VDZ might be doing more harm than good as discussed in the preceding section. However, extrapolating from the VDZ(4s3p1d) and VTZ basis sets with $\alpha$ $=2.6$, at no additional computational cost, results in a significantly lower RMSD of $0.02 \mathrm{kcal}$ $\mathrm{mol}^{-1}$.

Let us turn our attention to a more cost-effective approach, in which the (Q) contribution is obtained with a triple- $\zeta$-type basis set and the Q-(Q) contribution with a double- $\zeta$-type basis set. In particular, we will consider the following equations: 
$c \times[\mathrm{CCSDT}(\mathrm{Q}) / \mathrm{VTZ}-\mathrm{CCSDT} / \mathrm{VTZ}+\mathrm{CCSDTQ} / \mathrm{VDZ}-\mathrm{CCSDT}(\mathrm{Q}) / \mathrm{VDZ}]$

$c \times[\operatorname{CCSDT}(\mathrm{Q}) / \mathrm{V}\{\mathrm{D}, \mathrm{T}\} \mathrm{Z}-\mathrm{CCSDT} / \mathrm{V}\{\mathrm{D}, \mathrm{T}\} \mathrm{Z}+\mathrm{CCSDTQ} / \mathrm{VDZ}-\mathrm{CCSDT}(\mathrm{Q}) / \mathrm{VDZ}]$

$c \times[\operatorname{CCSDT}(\mathrm{Q}) / \mathrm{V}\{\mathrm{D}(4 \mathrm{~s} 3 \mathrm{p} 1 \mathrm{~d}), \mathrm{T}\} \mathrm{Z}-\mathrm{CCSDT} / \mathrm{V}\{\mathrm{D}(4 \mathrm{~s} 3 \mathrm{p} 1 \mathrm{~d}), \mathrm{T}\} \mathrm{Z}+\mathrm{CCSDTQ} / \mathrm{VDZ}-$ $\operatorname{CCSDT}(\mathrm{Q}) / \mathrm{VDZ}]$

$c \times[\operatorname{CCSDT}(\mathrm{Q}) / \mathrm{V}\{\mathrm{D}(4 \mathrm{~s} 3 \mathrm{p} 1 \mathrm{~d}), \mathrm{T}\} \mathrm{Z}-\operatorname{CCSDT} / \mathrm{V}\{\mathrm{D}(4 \mathrm{~s} 3 \mathrm{p} 1 \mathrm{~d}), \mathrm{T}\} \mathrm{Z}+\operatorname{CCSDTQ} / \operatorname{VDZ}(3 \mathrm{~s} 2 \mathrm{p})-$ $\operatorname{CCSDT}(\mathrm{Q}) / \operatorname{VDZ}(3 \mathrm{~s} 2 \mathrm{p})]$

$\operatorname{CCSDT}(\mathrm{Q}) / \mathrm{V}\{\mathrm{D}(4 \mathrm{~s} 3 \mathrm{p} 1 \mathrm{~d}), \mathrm{T}\} Z-\operatorname{CCSDT} / \mathrm{V}\{\mathrm{D}(4 \mathrm{~s} 3 \mathrm{p} 1 \mathrm{~d}), \mathrm{T}\} \mathrm{Z}+c \times[\operatorname{CCSDTQ} / \mathrm{VDZ}(3 \mathrm{~s} 2 \mathrm{p})-$ $\operatorname{CCSDT}(\mathrm{Q}) / \operatorname{VDZ}(3 \mathrm{~s} 2 \mathrm{p})]$

We begin by noting that equations (1) and (2) have the same computational cost and that the W4 method uses equation (1) with $c=1.10$. For the seven diatomics for which we have $\mathrm{V}\{\mathrm{T}, \mathrm{Q}\} \mathrm{Z}$ basis-set limit results, the $\mathrm{W} 4$ approach results in a relatively large RMSD of $0.043 \mathrm{kcal} \mathrm{mol}^{-1}$ and largest deviations of $+0.067\left(\mathrm{C}_{2}\right)$ and $-0.066\left(\mathrm{~S}_{2}\right) \mathrm{kcal} \mathrm{mol}^{-1}$. These results are shown in Table 8. We note that optimizing the scaling factor results in $c=1.09$ and essentially no change in the error statistics. Let us turn our attention to extrapolating the (Q) contribution from the $\mathrm{V}\{\mathrm{D}, \mathrm{T}\} \mathrm{Z}$ basis set pair and calculating the $\mathrm{Q}-(\mathrm{Q})$ component with the VDZ basis set. Using equation (2) with $c=1.06$ and using $\alpha=6.3$ in the (Q) extrapolation results in an RMSD of $0.037 \mathrm{kcal} \mathrm{mol}^{-1}$ and a largest deviation of $-0.069 \mathrm{kcal}$ $\mathrm{mol}^{-1}$ for $\mathrm{S}_{2}$. This does not represent a significant improvement over the W4 approach (i.e., eq. (1) with $c=1.10$ ). However, extrapolating the (Q) contribution from the $\mathrm{V}\{\mathrm{D}(4 \mathrm{~s} 3 \mathrm{p} 1 \mathrm{~d}), \mathrm{T}\} \mathrm{Z}$ basis set pair (via eq. 3 ) with $\alpha=3.0$ in the extrapolation, and using $c=$ 1.0 results in an RMSD of merely $0.016 \mathrm{kcal} \mathrm{mol}^{-1}$ and largest deviations of $+0.026\left(\mathrm{C}_{2}\right)$ and $-0.026\left(\mathrm{O}_{2}\right) \mathrm{kcal} \mathrm{mol}^{-1}$. This approach does not only outperform equations (1) and (2) but also requires no scaling factor (i.e., $c=1.0$ ) and no optimization of the extrapolation exponent 
(i.e., $\alpha=3.0$ ). We note that optimization of either or both of these parameters does not lead to an improvement in performance.

Table 8. Cost-effective approaches for calculating the connected quadruples contribution, CCSDTQ-CCSDT, to the total atomization energy for the set of seven diatomic molecules for which we were able to obtain basis-set limit values from $\mathrm{V}\{\mathrm{T}, \mathrm{Q}\} \mathrm{Z}$ extrapolations. The last column lists the TAEs extrapolated from the $\mathrm{V}\{\mathrm{T}, \mathrm{Q}\} \mathrm{Z}$ basis sets, the tabulated values in the other columns are deviations relative to these basis-set limit values (in $\mathrm{kcal} \mathrm{mol}^{-1}$ ).

\begin{tabular}{lcccccc}
\hline Eq. & $(1)$ & $(2)$ & $(3)$ & $(4)$ & $(5)$ & \\
$(\mathrm{Q})$ & $\mathrm{VTZ}$ & $\mathrm{V}\{\mathrm{D}, \mathrm{T}\} \mathrm{Z}$ & $\mathrm{V}\{\mathrm{D}(4 \mathrm{~s} 3 \mathrm{p} 1 \mathrm{~d}), \mathrm{T}\} \mathrm{Z}$ & $\mathrm{V}\{\mathrm{D}(4 \mathrm{~s} 3 \mathrm{p} 1 \mathrm{~d}), \mathrm{T}\} \mathrm{Z}$ & $\mathrm{V}\{\mathrm{D}(4 \mathrm{~s} 3 \mathrm{p} 1 \mathrm{~d}), \mathrm{T}\} \mathrm{Z}$ & $\mathrm{V}\{\mathrm{T}, \mathrm{Q}\} Z$ \\
$\mathrm{Q}-(\mathrm{Q})$ & $\mathrm{VDZ}$ & $\mathrm{VDZ}$ & $\mathrm{VDZ}$ & $\mathrm{VDZ}(3 \mathrm{~s} 2 \mathrm{p})$ & $\mathrm{VDZ}(3 \mathrm{~s} 2 \mathrm{p})$ & $\mathrm{V}\{\mathrm{T}, \mathrm{Q}\} Z$ \\
$\mathrm{c}$ & 1.10 & 1.06 & 1.0 & 1.0 & 0.96 & $\mathrm{~N} / \mathrm{A}$ \\
$\alpha^{a}$ & $\mathrm{~N} / \mathrm{A}$ & 6.3 & 3.0 & 3.0 & 3.0 & 3.0 \\
\hline $\mathrm{BN}$ & 0.054 & 0.026 & 0.010 & 0.286 & -0.041 & 2.079 \\
$\mathrm{C}_{2}$ & 0.067 & 0.031 & 0.026 & -0.201 & 0.051 & 2.301 \\
$\mathrm{O}_{2}$ & 0.020 & -0.021 & -0.026 & 0.012 & -0.005 & 1.045 \\
$\mathrm{FO}$ & 0.005 & -0.015 & 0.004 & 0.029 & -0.010 & 0.540 \\
$\mathrm{P}_{2}$ & -0.025 & -0.043 & -0.003 & -0.042 & -0.004 & 1.481 \\
$\mathrm{~S}_{2}$ & -0.066 & -0.069 & -0.014 & 0.072 & -0.015 & 0.887 \\
$\mathrm{ClO}$ & -0.019 & -0.026 & 0.014 & 0.061 & -0.003 & 0.630 \\
\hline $\mathrm{RMSD}^{b, c}$ & 0.043 & 0.037 & 0.016 & 0.138 & 0.026 & \\
$\mathrm{MAD}^{b, c}$ & 0.036 & 0.033 & 0.014 & 0.100 & 0.019 & \\
$\mathrm{MSD}^{b, c}$ & 0.005 & -0.017 & 0.001 & 0.031 & -0.004 & \\
\hline $\mathrm{EPp}^{2}$ &
\end{tabular}

${ }^{a}$ Exponent used in the extrapolation of the (Q) component.

${ }^{b}$ See footnote $a$ to Table 2 .

${ }^{c}$ Error statistics with respect to the $\mathrm{V}\{\mathrm{T}, \mathrm{Q}\} \mathrm{Z}$ reference values.

Equation (3) still requires calculating the CCSDTQ energy with the VDZ basis set. Using the $\operatorname{VDZ}(3 \mathrm{~s} 2 \mathrm{p})$ basis set instead of the VDZ basis set would represent a significant saving in computational cost. Equation (4) extrapolates the (Q) component from the VDZ(4s3p1d) and VTZ basis sets and calculates the Q-(Q) contribution with the VDZ(3s2p) basis set. With $c=1.0$ and $\alpha=3.0$, this results in a significant deterioration in performance relative to eq. (3). In particular, the RMSD is increased by an order of magnitude, from 0.016 (eq. 3) to 0.138 (eq. 4) $\mathrm{kcal} \mathrm{mol}^{-1}$. Optimizing the scaling factor and extrapolation exponent does not alleviate the situation and results only in a minor improvement in performance (i.e., RMSD $\left.=0.128 \mathrm{kcal} \mathrm{mol}^{-1}\right)$. On the other hand, using eq. (5), which only scales the Q-(Q) component, results in a respectable RMSD of $0.026 \mathrm{kcal} \mathrm{mol}^{-1}$ at a significantly reduced 
computational cost. We note that this approach uses only one adjustable parameter (i.e., a scaling factor of $c=0.96$ ).

Having established that equation (3) with $c=1.0$ and $\alpha=3.0$ leads to an RMSD of merely $0.016 \mathrm{kcal} \mathrm{mol}^{-1}$ and a MAD of merely $0.005 \mathrm{kcal} \mathrm{mol}^{-1}$ relative to $\mathrm{V}\{\mathrm{T}, \mathrm{Q}\} \mathrm{Z}$ results, we can use these reference values to evaluate the performance of more approximate approaches. These results are presented in Table 9 for our set of 21 challenging systems. We start by noting that for all the systems the overall CCSDTQ-CCSDT contribution to the TAE is fairly large. Apart from $\mathrm{FO}, \mathrm{ClO}$, and $\mathrm{S}_{2}$ this contribution exceeds $1 \mathrm{kcal} \mathrm{mol}^{-1}$ for all the systems, and even exceeds $2 \mathrm{kcal} \mathrm{mol}^{-1}$ for as much as ten systems. Particularly large contributions of over $3 \mathrm{kcal} \mathrm{mol}^{-1}$ are obtained for $\mathrm{ClOO}$ (3.09), $\mathrm{O}_{3}$ (3.64), and $\mathrm{S}_{4}$ (4.94 kcal $\left.\mathrm{mol}^{-1}\right)$.

Let us turn our attention to the performance of cost-effective approximations for the CCSDTQ-CCSDT component to the TAE for our set of 21 molecules (Table 9). Calculating the CCSDTQ-CCSDT contribution in conjunction with the VDZ(3s2p) basis set and scaling by 1.4 results in poor performance with an unacceptably high RMSD of $0.72 \mathrm{kcal} \mathrm{mol}^{-1}$. As may be expected, particularly large underestimations are obtained for systems containing multiple second-row atoms, e.g., $1.83\left(\mathrm{~S}_{4}\right), 1.04\left(\mathrm{~S}_{3}\right), 0.91\left(\mathrm{P}_{4}\right) \mathrm{kcal} \mathrm{mol}^{-1}$. Calculating the $(\mathrm{Q})$ part with the larger VDZ basis set significantly improves the performance and results in an overall RMSD of $0.34 \mathrm{kcal} \mathrm{mol}^{-1}$. However, fairly large underestimations are still obtained for systems containing multiple second-row atoms, e.g., $0.54\left(\mathrm{~S}_{4}\right)$ and $0.51\left(\mathrm{P}_{4}\right) \mathrm{kcal} \mathrm{mol}^{-1}$, and fairly large overestimations are obtained for highly multireference systems, e.g., 0.62 $\left(\mathrm{O}_{3}\right) \mathrm{kcal} \mathrm{mol}^{-1}$. Further increasing the basis set size in the $(\mathrm{Q})$ part to the VDZ(4s3p1d) basis set reduces the RMSD to $0.25 \mathrm{kcal} \mathrm{mol}^{-1}$, and is therefore recommended for large systems. We note, however, that fairly large deviations are obtained for systems containing many second-row atoms and/or strongly multireference systems. For example, for $\mathrm{S}_{4}, \mathrm{P}_{4}$, and $\mathrm{S}_{3}$ 
underestimations of $0.4-0.5 \mathrm{kcal} \mathrm{mol}^{-1}$ are obtained, whilst for $\mathrm{BN}$ and $\mathrm{O}_{3}$ overestimations of $0.3-0.4 \mathrm{kcal} \mathrm{mol}^{-1}$ are obtained.

Table 9. Performance of cost-effective approaches for obtaining the connected quadruples contribution, CCSDTQ-CCSDT, to the total atomization energy for the set of 21 molecules for which we were able to obtain reference values via eq. 3 (i.e., extrapolating the (Q) contribution from the VDZ(4s3p1d) and VTZ basis sets and calculating the Q-(Q) contribution with the VDZ basis set). The reference TAEs are listed in the last column, the other columns list deviations from these reference values (in $\mathrm{kcal} \mathrm{mol}^{-1}$ ).

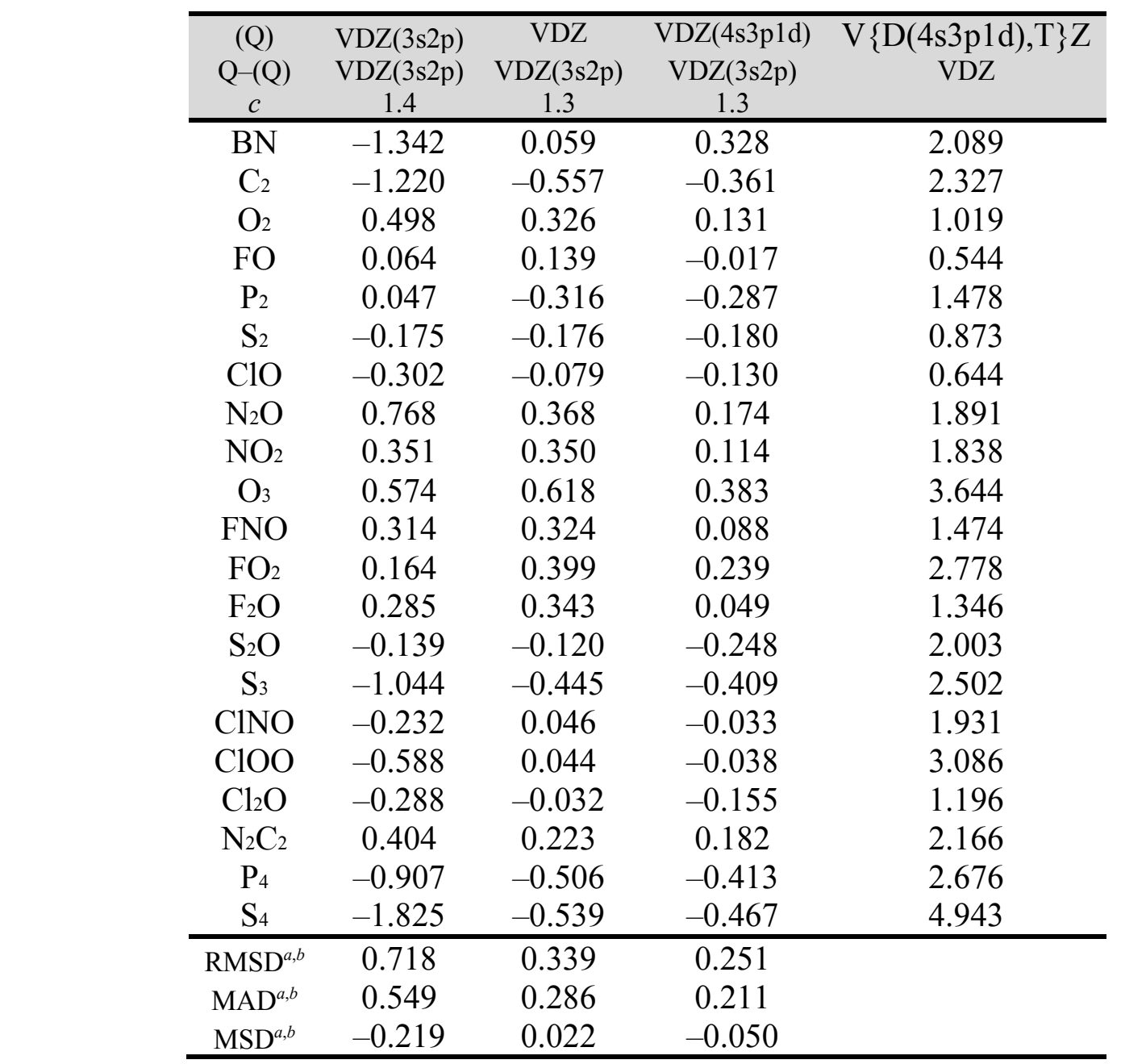

${ }^{a}$ See footnote $a$ to Table 2 .

${ }^{b}$ Error statistics with respect to reference values obtained via eq. (3) for the 21 systems above. 
3.5 Perturbative, noniterative connected quintuple excitations. For the set of seven diatomics we were able to extrapolate the CCSDTQ(5)-CCSDTQ contribution from the VDZ and VTZ basis sets. These results are presented in Table 10 along with results for the VDZ(3s2p), VDZ, VDZ(4s3p1d), and VTZ basis sets. Consistent with previous studies, ${ }^{37,8}$ the (5) contribution to the TAE converges fairly rapidly to the basis-set limit. We begin with evaluating the performance of the rather small VDZ(3s2p) basis set and note that for systems with more than four non-hydrogen atoms this would normally be the only feasible option with current mainstream technology. For the seven diatomic systems in Table 10 the $\operatorname{VDZ}(3 \mathrm{~s} 2 \mathrm{p})$ basis set attains a fairly large RMSD of $0.090 \mathrm{kcal} \mathrm{mol}^{-1}$. We note, however, that the VDZ(3s $2 p)$ basis set gives fairly good results for all the systems apart from the highly multireference BN system. Once this system is eliminated the RMSD is reduced to merely $0.022 \mathrm{kcal} \mathrm{mol}^{-1}$. The error for the BN system is reduced from $0.233 \mathrm{kcal} \mathrm{mol}^{-1}$ for the $\operatorname{VDZ}(3 \mathrm{~s} 2 \mathrm{p})$ basis set to $0.066 \mathrm{kcal} \mathrm{mol}^{-1}$ for the VDZ basis set. Thus, for strongly multireference and polar systems are considered we would recommend using the VDZ basis set. The overall RMSD for the VDZ basis set is $50 \%$ of that for the VDZ(3s $2 \mathrm{p})$ basis set, namely it is $0.045 \mathrm{kcal} \mathrm{mol}^{-1}$. Increasing the basis set size to VDZ(4s3p1d) results in another significant reduction in the RMSD to merely $0.017 \mathrm{kcal} \mathrm{mol}^{-1}$, and the VTZ basis set leads to an RMSD of $0.013 \mathrm{kcal} \mathrm{mol}^{-1}$. 
Table 10. Convergence of the noniterative connected quintuples contribution, CCSDTQ(5)CCSDTQ, to the total atomization energy for the set of seven diatomic molecules for which we were able to obtain basis-set limit values from $\mathrm{V}\{\mathrm{D}, \mathrm{T}\} \mathrm{Z}$ extrapolations. The reference TAEs are listed in the last column, the other columns list deviations from these reference values (in $\mathrm{kcal} \mathrm{mol}^{-1}$ ).

${ }^{a}$ See footnote $a$ to Table 2 .

\begin{tabular}{lccccc}
\hline & VDZ(3s2p) & VDZ & VDZ(4s3p1d) & VTZ & V $\{\mathrm{D}, \mathrm{T}\} Z$ \\
\hline $\mathrm{BN}$ & 0.233 & 0.066 & -0.034 & 0.019 & -0.175 \\
$\mathrm{C}_{2}$ & 0.031 & 0.094 & -0.003 & 0.028 & 0.371 \\
$\mathrm{O}_{2}$ & -0.025 & -0.011 & -0.010 & -0.003 & 0.119 \\
$\mathrm{FO}$ & 0.018 & 0.018 & 0.008 & 0.005 & 0.024 \\
$\mathrm{P}_{2}$ & 0.025 & 0.023 & 0.022 & 0.007 & 0.081 \\
$\mathrm{~S}_{2}$ & -0.012 & 0.012 & 0.014 & 0.004 & 0.037 \\
$\mathrm{ClO}$ & -0.009 & 0.007 & 0.002 & 0.002 & 0.032 \\
\hline $\mathrm{RMSD}^{\mathrm{a}, \mathrm{b}}$ & 0.090 & 0.045 & 0.017 & 0.013 & \\
MAD $^{\mathrm{a}, \mathrm{b}}$ & 0.050 & 0.033 & 0.013 & 0.010 & \\
MSD $^{\mathrm{a}, \mathrm{b}}$ & 0.037 & 0.030 & 0.000 & 0.009 & \\
\hline
\end{tabular}

${ }^{b}$ Error statistics with respect to the $\mathrm{V}\{\mathrm{D}, \mathrm{T}\} \mathrm{Z}$ reference values.

The results in Table 10 show that, in conjunction with the VDZ(4s3p1d) basis set, the (5) contribution to the TAE is almost converged to the CBS limit. We were able to obtain the (5) contribution to the TAE in conjunction with the VDZ(4s3p1d) basis set for 17 molecules (namely, all the molecules in Table 9 apart from $\mathrm{FO}_{2}, \mathrm{ClOO}, \mathrm{P}_{4}$, and $\mathrm{S}_{4}$ ). These results are presented in Table S2 of the Supplementary Information. The (5)/VDZ(4s3p1d) contribution to the TAE is positive, with the exception of $\mathrm{BN}$ and FNO for which it is -0.208 and -0.038 $\mathrm{kcal} \mathrm{mol}^{-1}$, respectively. For the other systems the (5)/VDZ(4s3p1d) contribution to the TAE ranges between $0.009(\mathrm{ClNO})$ and $0.451\left(\mathrm{O}_{3}\right) \mathrm{kcal} \mathrm{mol}^{-1}$. Where for five systems the (5) contribution to the TAE exceeds $0.1 \mathrm{kcal} \mathrm{mol}^{-1}$, namely: $\mathrm{P}_{2}(0.103), \mathrm{O}_{2}(0.109), \mathrm{N}_{2} \mathrm{C}_{2}(0.205)$, $\mathrm{C}_{2}(0.368)$, and $\mathrm{O}_{3}\left(0.451 \mathrm{kcal} \mathrm{mol}^{-1}\right)$.

Relative to the VDZ(4s3p1d) results for the abovementioned 17 systems, the VDZ(3s2p) basis set attains an RMSD of $0.079 \mathrm{kcal} \mathrm{mol}^{-1}$. Exclusion of the BN system from the error statistics results in an RMSD of $0.047 \mathrm{kcal} \mathrm{mol}^{-1}$. Apart from BN, all the deviations 
are smaller or equal to $0.1 \mathrm{kcal} \mathrm{mol}^{-1}$. The largest deviations being $0.10\left(\mathrm{NO}_{2}\right), 0.09\left(\mathrm{~S}_{2} \mathrm{O}\right)$, and 0.07 (FNO and ClNO) $\mathrm{kcal} \mathrm{mol}^{-1}$.

3.6 Full-iterative connected quintuple excitations. For our set of seven diatomics we were able to extrapolate the CCSDTQ5-CCSDTQ(5) contribution from the VDZ and VTZ basis sets. These results are presented in Table 11 along with results for the VDZ(3s $2 p)$, VDZ, VDZ(4s3p1d), and VTZ basis sets. We begin with evaluating the performance of the rather small VDZ(3s2p) basis set, which would be the only realistic choice for systems with more than four non-hydrogen atoms. For the seven diatomic systems in Table 11 the VDZ(3s2p) basis set attains a rather large RMSD of $0.118 \mathrm{kcal} \mathrm{mol}^{-1}$. This large RMSD is a result of very large deviations obtained for $\mathrm{BN}$ and $\mathrm{C}_{2}$ (Table 11). Elimination of these two challenging systems results in an RMSD of $0.051 \mathrm{kcal} \mathrm{mol}^{-1}$. The overall RMSD for the VDZ basis set is nearly $50 \%$ of that for the $\operatorname{VDZ}\left(3 \mathrm{~s} 2 \mathrm{p}\right.$ ) basis set, namely it is $0.069 \mathrm{kcal} \mathrm{mol}^{-1}$ (elimination of $\mathrm{BN}$ and $\mathrm{C}_{2}$ reduces the $\mathrm{RMSD}$ to $0.040 \mathrm{kcal} \mathrm{mol}^{-1}$ ). Increasing the basis set size to $\operatorname{VDZ}(4 \mathrm{~s} 3 \mathrm{p} 1 \mathrm{~d})$ results in another significant reduction in the RMSD to merely $0.037 \mathrm{kcal} \mathrm{mol}^{-}$ ${ }^{1}$. The VTZ basis set results in an RMSD of $0.020 \mathrm{kcal} \mathrm{mol}^{-1}$. 
Table 11. Convergence of the full-iterative connected quintuples contribution, CCSDTQ5CCSDTQ(5), to the total atomization energy for the set of seven diatomic molecules for which we were able to obtain basis-set limit values from $\mathrm{V}\{\mathrm{D}, \mathrm{T}\} \mathrm{Z}$ extrapolations. The reference TAEs are listed in the last column, the other columns list deviations from these reference values (in $\mathrm{kcal} \mathrm{mol}^{-1}$ ).

\begin{tabular}{lccccc}
\hline & VDZ(3s2p) & VDZ & VDZ(4s3p1d) & VTZ & V $\{\mathrm{D}, \mathrm{T}\} Z$ \\
\hline $\mathrm{BN}$ & -0.254 & -0.105 & -0.019 & -0.031 & 0.373 \\
$\mathrm{C}_{2}$ & -0.144 & -0.120 & -0.049 & -0.035 & -0.026 \\
$\mathrm{O}_{2}$ & 0.001 & -0.002 & -0.002 & -0.001 & -0.003 \\
$\mathrm{FO}$ & -0.028 & -0.024 & -0.013 & -0.007 & 0.015 \\
$\mathrm{P}_{2}$ & -0.096 & -0.071 & -0.068 & -0.021 & 0.091 \\
$\mathrm{~S}_{2}$ & -0.045 & -0.043 & -0.042 & -0.013 & 0.050 \\
$\mathrm{ClO}$ & -0.027 & -0.024 & -0.018 & -0.007 & 0.020 \\
\hline $\mathrm{RMSD}^{\mathrm{a}, \mathrm{b}}$ & 0.118 & 0.069 & 0.037 & 0.020 & \\
$\mathrm{MAD}^{\mathrm{a}, \mathrm{b}}$ & 0.085 & 0.055 & 0.030 & 0.016 & \\
$\mathrm{MSD}^{\mathrm{a}, \mathrm{b}}$ & -0.085 & -0.055 & -0.030 & -0.016 & \\
\hline
\end{tabular}

${ }^{a}$ See footnote $a$ to Table 2 .

${ }^{b}$ Error statistics with respect to the $\mathrm{V}\{\mathrm{D}, \mathrm{T}\} \mathrm{Z}$ reference values.

For all 21 systems we were able to obtain the 5-(5) contribution to the TAE in conjunction with the $\operatorname{VDZ}(3 \mathrm{~s} 2 \mathrm{p})$ basis set, and for 16 systems we were able to obtain this contribution with the VDZ basis set. These results are presented in Table S3 of the supplementary material. As indicated above the VDZ values are not sufficiently close to the basis-set limit to be used as reference values, nevertheless, it is worthwhile comparing between the VDZ and VDZ(3s2p) results. Relative to the VDZ values, the VDZ(3s2p) basis set attains an RMSD $0.035 \mathrm{kcal} \mathrm{mol}^{-1}$ (once BN is excluded, vide supra). Inspection of the $\operatorname{VDZ}(3 \mathrm{~s} 2 \mathrm{p})$ results reveals that for about half of the systems the 5-(5) contribution to the TAE is negative and for about half it is positive. The largest negative contributions to the TAE are obtained for $\mathrm{C}_{2}(-0.170), \mathrm{O}_{3}(-0.080), \mathrm{ClOO}(-0.051)$, and $\mathrm{FO}_{2}\left(-0.042 \mathrm{kcal} \mathrm{mol}^{-1}\right)$. The largest positive contributions to the TAE are obtained for $\mathrm{N}_{2} \mathrm{O}(0.159), \mathrm{BN}(0.120), \mathrm{S}_{4}$ (0.083), FNO (0.058), and CINO (0.039 $\left.\mathrm{kcal} \mathrm{mol}^{-1}\right)$. 
3.7 Connected quintuple excitations as a whole. In subsection 3.5 we examined the basis set convergence of the (5) component relative to $(5) / \mathrm{V}\{\mathrm{D}, \mathrm{T}\} \mathrm{Z}$ reference values. It is also of interest to evaluate the performance of the (5) component calculated with the $\operatorname{VDZ}(3 \mathrm{~s} 2 \mathrm{p})$, VDZ, VDZ(4s3p1d), and VTZ basis sets relative to the full connected quintuple, CCSDTQ5CCSDTQ, component. For our set of seven diatomics we were able to extrapolate the CCSDTQ5-CCSDTQ component to the basis-set limit from the VDZ and VTZ basis sets. These results are presented in Table 12 . Relative to the $5 / \mathrm{V}\{\mathrm{D}, \mathrm{T}\} \mathrm{Z}$ reference values, the (5)/VDZ(3s2p) results in a surprisingly small RMSD of $0.068 \mathrm{kcal} \mathrm{mol}^{-1}$. This is due to error cancelation between the neglect of the fully iterative quintuple excitations and basis set incompleteness errors. Indeed, the performance deteriorates significantly when larger basis sets are used, namely the RMSDs for the larger basis sets range between 0.128 (VDZ) to $0.157(\mathrm{VDZ}(4 \mathrm{~s} 3 \mathrm{p} 1 \mathrm{~d})) \mathrm{kcal} \mathrm{mol}^{-1}$.

Table 12. Performance of the CCSDTQ(5)-CCSDTQ and CCSDTQ5-CCSDTQ contributions to the total atomization energy for a set of seven diatomic molecules relative to the CCSDTQ5-CCSDTQ contribution extrapolated from the $\mathrm{V}\{\mathrm{D}, \mathrm{T}\} \mathrm{Z}$ basis set pair. The reference TAEs are listed in the last column, the other columns list deviations from these reference values (in $\mathrm{kcal} \mathrm{mol}^{-1}$ ).

\begin{tabular}{|c|c|c|c|c|c|c|c|c|c|}
\hline & $\begin{array}{c}(5) \\
\operatorname{VDZ}(3 \mathrm{~s} 2 \mathrm{p})\end{array}$ & $\begin{array}{c}(5) \\
\text { VDZ }\end{array}$ & $\begin{array}{c}(5) \\
\operatorname{VDZ}(4 \mathrm{~s} 3 \mathrm{p} 1 \mathrm{~d})\end{array}$ & $\begin{array}{c}(5) \\
\text { VTZ }\end{array}$ & $\begin{array}{c}5 \\
\operatorname{VDZ}(3 \mathrm{~s} 2 \mathrm{p})\end{array}$ & $\begin{array}{c}5 \\
\mathrm{VDZ}\end{array}$ & $\begin{array}{c}5 \\
\operatorname{VDZ}(4 \mathrm{~s} 3 \mathrm{p} 1 \mathrm{~d})\end{array}$ & $\begin{array}{c}5 \\
\text { VTZ }\end{array}$ & $\begin{array}{c}5 \\
\mathrm{~V}\{\mathrm{D}, \mathrm{T}\} \mathrm{Z}\end{array}$ \\
\hline $\mathrm{BN}$ & -0.141 & -0.308 & -0.407 & -0.354 & -0.021 & -0.039 & -0.053 & -0.012 & 0.199 \\
\hline $\mathrm{C}_{2}$ & 0.058 & 0.121 & 0.023 & 0.054 & -0.112 & -0.025 & -0.052 & -0.007 & 0.345 \\
\hline $\mathrm{O}_{2}$ & -0.023 & -0.008 & -0.007 & 0.000 & -0.024 & -0.013 & -0.012 & -0.004 & 0.116 \\
\hline FO & 0.003 & 0.004 & -0.007 & -0.009 & -0.011 & -0.005 & -0.005 & -0.002 & 0.039 \\
\hline $\mathrm{P}_{2}$ & -0.066 & -0.068 & -0.069 & -0.084 & -0.072 & -0.047 & -0.045 & -0.014 & 0.172 \\
\hline $\mathrm{S}_{2}$ & -0.062 & -0.038 & -0.037 & -0.047 & -0.057 & -0.031 & -0.028 & -0.009 & 0.088 \\
\hline $\mathrm{ClO}$ & -0.030 & -0.014 & -0.019 & -0.018 & -0.036 & -0.017 & -0.016 & -0.005 & 0.053 \\
\hline $\mathrm{RMSD}^{\mathrm{a}, \mathrm{b}}$ & 0.068 & 0.128 & 0.157 & 0.140 & 0.058 & 0.029 & 0.035 & 0.009 & \\
\hline $\mathrm{MAD}^{\mathrm{a}, \mathrm{b}}$ & 0.055 & 0.080 & 0.081 & 0.081 & 0.048 & 0.025 & 0.030 & 0.008 & \\
\hline $\mathrm{MSD}^{\mathrm{a}, \mathrm{b}}$ & -0.037 & -0.044 & -0.075 & -0.066 & -0.048 & -0.025 & -0.030 & -0.008 & \\
\hline
\end{tabular}

${ }^{a}$ See footnote $a$ to Table 2 .

${ }^{b}$ Error statistics with respect to the CCSDTQ5/V $\{\mathrm{D}, \mathrm{T}\} \mathrm{Z}-\mathrm{CCSDTQ} / \mathrm{V}\{\mathrm{D}, \mathrm{T}\} \mathrm{Z}$ reference values for the seven systems above.

What about calculating the CCSDTQ5-CCSDTQ component in conjunction with small basis sets. The VDZ(3s $2 \mathrm{p})$ basis set results in an RMSD of $0.058 \mathrm{kcal} \mathrm{mol}^{-1}$ and seems to be a fairly robust and cost-effective option. Adding the $\mathrm{d}$ function from the VDZ basis set, 
however, cuts the RMSD by $50 \%$ to $0.029 \mathrm{kcal} \mathrm{mol}^{-1}$, thus this would be the recommended option in case it is computationally affordable. The VDZ(4s3p1d) basis set results in a similar performance and is therefore not recommended. Finally, we note that the VTZ basis set gives results that are essentially identical to the $\mathrm{V}\{\mathrm{D}, \mathrm{T}\} \mathrm{Z}$ results, i.e., $\mathrm{RMSD}=0.009 \mathrm{kcal} \mathrm{mol}^{-1}$ and the deviations (all underestimations) are smaller or equal to $0.01 \mathrm{kcal} \mathrm{mol}^{-1}$.

For a set of 15 di and triatomics we were able to obtain the CCSDTQ5-CCSDTQ contribution to the TAE in conjunction with the VDZ basis set. Although these values are not sufficiently close to the basis-set limit to be used as reference values, it is worthwhile comparing between the VDZ and VDZ(3s2p) results. For the set of 15 systems we obtain an overall RMSD of $0.030 \mathrm{kcal} \mathrm{mol}^{-1}$, with only one deviation (for $\mathrm{C}_{2}$ ) above $0.04 \mathrm{kcal} \mathrm{mol}^{-1}$. This is another indication that calculating the CCSDTQ5-CCSDTQ contribution in conjunction with the $\operatorname{VDZ}(3 \mathrm{~s} 2 \mathrm{p})$ is a cost-effective option.

Finally, a note is due on the magnitude of the CCSDTQ5-CCSDTQ contribution in conjunction with the VDZ(3s2p) basis set, which were able to obtain for all the 21 systems in our set. The CCSDTQ5-CCSDTQ contribution to the TAE spans a wide interval, ranging from $0.017(\mathrm{ClO})$ to $0.395\left(\mathrm{O}_{3}\right) \mathrm{kcal} \mathrm{mol}^{-1}$. For most systems (13 out of 21) the CCSDTQ5CCSDTQ contribution exceeds $0.1 \mathrm{kcal} \mathrm{mol}^{-1}$, and for six of these it exceeds $0.2 \mathrm{kcal} \mathrm{mol}^{-1}$, namely for $\mathrm{ClOO}(0.222), \mathrm{N}_{2} \mathrm{C}_{2}(0.229), \mathrm{FO}_{2}(0.230), \mathrm{C}_{2}(0.232), \mathrm{S}_{4}(0.291)$, and $\mathrm{O}_{3}(0.395$ $\left.\mathrm{kcal} \mathrm{mol}^{-1}\right)$.

3.8 Connected sextuple excitations. Contributions beyond CCSDTQ5 can still be chemically significant for systems dominated by moderate-to-severe multireference effects. Table 13 gathers the CCSDTQ5(6) - CCSDTQ5 contribution to the TAE calculated in conjunction with the VDZ(3s2p), VDZ, VDZ(4s3p1d), VTZ, and V $\{D, T\} Z$ basis sets, as well as the CCSDTQ56 - CCSDTQ5(6) contribution to the TAE calculated in conjunction with 
the VDZ(3s2p) basis set. Let us begin by considering the basis set convergence of the CCSDTQ5(6) - CCSDTQ5 component. For three systems $\left(\mathrm{BN}, \mathrm{C}_{2}\right.$, and $\left.\mathrm{P}_{2}\right)$ we were able to obtain the (6) contribution with the $\mathrm{V}\{\mathrm{D}, \mathrm{T}\} \mathrm{Z}$ basis set pair. The highly multireference $\mathrm{BN}$ diatomic exhibits a somewhat slow basis-set convergence. At the $(6) / V\{D, T\} Z$ level of theory we obtain a value of $-0.011 \mathrm{kcal} \mathrm{mol}^{-1}$. Both the VDZ(4s3p1d) and VTZ basis sets overshoot this value by about $0.008 \mathrm{kcal} \mathrm{mol}^{-1}$. The VDZ and VDZ(3s $\left.2 \mathrm{p}\right)$ basis sets overshoot this value by as much as 0.025 and $0.067 \mathrm{kcal} \mathrm{mol}^{-1}$, respectively. Nevertheless, for the other two systems for which we have $(6) / V\{D, T\} Z$ basis-set limit values $\left(\mathrm{C}_{2}\right.$ and $\left.\mathrm{P}_{2}\right)$, the VDZ and VTZ basis sets are practically spot on the $(6) / \mathrm{V}\{\mathrm{D}, \mathrm{T}\} \mathrm{Z}$ values, and even the VDZ(3s2p) basis set results in deviations smaller or equal to $0.01 \mathrm{kcal} \mathrm{mol}^{-1}$. 
Table 13. Overview of basis set convergence of the CCSDTQ5(6) - CCSDTQ5 contribution to the total atomization energy and the magnitude of the CCSDTQ56 - CCSDTQ5(6) contribution calculated with the $\operatorname{VDZ}\left(3 \mathrm{~s} 2 \mathrm{p}\right.$ ) basis set (in $\left.\mathrm{kcal} \mathrm{mol}^{-1}\right)$.

\begin{tabular}{|c|c|c|c|c|c|c|c|}
\hline & $\begin{array}{c}(6) \\
\operatorname{VDZ}(3 \mathrm{~s} 2 \mathrm{p}) \\
\end{array}$ & $\begin{array}{c}(6) \\
\text { VDZ }\end{array}$ & $\begin{array}{c}(6) \\
\operatorname{VDZ}(4 \mathrm{~s} 3 \mathrm{p} 1 \mathrm{~d}) \\
\end{array}$ & $\begin{array}{c}(6) \\
\text { VTZ } \\
\end{array}$ & $\begin{array}{c}(6) \\
\mathrm{V}\{\mathrm{D}, \mathrm{T}\} \mathrm{Z} \\
\end{array}$ & $\begin{array}{c}6-(6) \\
\operatorname{VDZ}(3 \mathrm{~s} 2 \mathrm{p}) \\
\end{array}$ & $\begin{array}{c}6 \\
\operatorname{VDZ}(3 \mathrm{~s} 2 \mathrm{p}) \\
\end{array}$ \\
\hline $\mathrm{BN}$ & 0.056 & 0.014 & -0.004 & -0.003 & -0.011 & -0.026 & 0.030 \\
\hline $\mathrm{C}_{2}$ & 0.065 & 0.061 & 0.057 & 0.060 & 0.060 & 0.003 & 0.069 \\
\hline $\mathrm{O}_{2}$ & 0.012 & 0.011 & 0.010 & & & 0.002 & 0.014 \\
\hline FO & 0.003 & 0.003 & 0.001 & & & 0.000 & 0.003 \\
\hline $\mathrm{P}_{2}$ & 0.020 & 0.010 & 0.011 & 0.010 & 0.010 & 0.006 & 0.026 \\
\hline $\mathrm{S}_{2}$ & 0.003 & 0.004 & 0.004 & & & 0.001 & 0.004 \\
\hline $\mathrm{ClO}$ & 0.001 & 0.003 & 0.002 & & & 0.000 & 0.001 \\
\hline $\mathrm{N}_{2} \mathrm{O}$ & 0.010 & & & & & 0.015 & 0.025 \\
\hline $\mathrm{NO}_{2}$ & 0.017 & & & & & 0.003 & 0.020 \\
\hline $\mathrm{O}_{3}$ & 0.055 & & & & & -0.001 & 0.053 \\
\hline FNO & 0.003 & & & & & 0.006 & 0.009 \\
\hline $\mathrm{FO}_{2}$ & 0.026 & & & & & & \\
\hline $\mathrm{F}_{2} \mathrm{O}$ & 0.010 & & & & & 0.001 & 0.010 \\
\hline $\mathrm{S}_{2} \mathrm{O}$ & 0.015 & & & & & 0.003 & 0.018 \\
\hline $\mathrm{S}_{3}$ & 0.011 & & & & & 0.003 & 0.014 \\
\hline CINO & 0.007 & & & & & 0.004 & 0.012 \\
\hline $\mathrm{ClOO}$ & 0.023 & & & & & & \\
\hline $\mathrm{Cl}_{2} \mathrm{O}$ & 0.006 & & & & & 0.001 & 0.007 \\
\hline $\mathrm{N}_{2} \mathrm{C}_{2}$ & 0.023 & & & & & 0.003 & 0.026 \\
\hline $\mathrm{P}_{4}$ & 0.020 & & & & & & \\
\hline $\mathrm{S}_{4}$ & 0.030 & & & & & & \\
\hline
\end{tabular}

For the seven diatomics in our set we were able to calculate the (6) contribution in conjunction with the $\operatorname{VDZ}(4 \mathrm{~s} 3 \mathrm{p} 1 \mathrm{~d})$ basis set. Relative to these values, the VDZ and VDZ(3s2p) basis sets attain RMSDs of 0.002 and $0.005 \mathrm{kcal} \mathrm{mol}^{-1}$, respectively (after exclusion of the problematic BN system). Thus, it seems that the (6)/VDZ(3s $2 p)$ contribution is fairly close to the basis-set limit. With that in mind, it is useful to examine the magnitude of the (6)/VDZ(3s2p) contribution for our set of 21 systems (Table 13). For most of the systems the (6) contribution ranges between 0.00 and $0.03 \mathrm{kcal} \mathrm{mol}^{-1}$, however for three strongly multireference systems $\left(\mathrm{BN}, \mathrm{C}_{2}\right.$, and $\left.\mathrm{O}_{3}\right)$ it ranges between 0.05 and $0.07 \mathrm{kcal} \mathrm{mol}^{-1}$.

With the exception of $\mathrm{FO}_{2}, \mathrm{ClOO}, \mathrm{P}_{4}$ and $\mathrm{S}_{4}$ we were able to obtain the CCSDTQ56 CCSDTQ5 contribution in conjunction with the $\operatorname{VDZ}(3 \mathrm{~s} 2 \mathrm{p})$ basis set for all the molecules in our set (Table 13). For most of the systems this contribution is equal or smaller than $0.01 \mathrm{kcal}$ 
$\mathrm{mol}^{-1}$. Nevertheless, we find that for six systems the CCSDTQ56 - CCSDTQ5 contribution ranges between $0.02-0.03 \mathrm{kcal} \mathrm{mol}^{-1}$. These systems are: $\mathrm{S}_{2} \mathrm{O}(0.018), \mathrm{NO}_{2}(0.020), \mathrm{N}_{2} \mathrm{O}$ (0.025), $\mathrm{P}_{2}(0.026), \mathrm{N}_{2} \mathrm{C}_{2}(0.026)$, and $\mathrm{BN}\left(0.030 \mathrm{kcal} \mathrm{mol}^{-1}\right)$. Whilst for the strongly multireference molecules $\mathrm{O}_{3}$ and $\mathrm{C}_{2}$ the CCSDTQ56 - CCSDTQ5 contribution is 0.053 and $0.069 \mathrm{kcal} \mathrm{mol}^{-1}$, respectively.

3.9 Connected septuple excitations. For the sake of completeness, we have calculated the CCSDTQ56(7) - CCSDTQ56, CCSDTQ567 - CCSDTQ56(7), and CCSDTQ567 CCSDTQ56 contributions to the TAE for a subset of 15 systems. As expected these contributions are practically nil for all the systems including the strongly multireference systems. In particular, the largest CCSDTQ567 - CCSDTQ56 contributions to the TAE are obtained for $\mathrm{BN}(0.003), \mathrm{C}_{2}(0.004)$, and $\mathrm{O}_{3}\left(0.005 \mathrm{kcal} \mathrm{mol}^{-1}\right)$.

Table 14. Overview of the magnitude of the CCSDTQ56(7) - CCSDTQ56, CCSDTQ567 CCSDTQ56(7), and CCSDTQ567 - CCSDTQ56 contributions to the total atomization energy calculated with the $\operatorname{VDZ}\left(3 \mathrm{~s} 2 \mathrm{p}\right.$ ) basis set (in $\left.\mathrm{kcal} \mathrm{mol}^{-1}\right)$.

\begin{tabular}{cccc}
\hline & $(7)$ & $7-(7)$ & 7 \\
\hline $\mathrm{BN}$ & -0.003 & 0.005 & 0.003 \\
$\mathrm{C}_{2}$ & 0.003 & 0.001 & 0.004 \\
$\mathrm{O}_{2}$ & 0.001 & 0.000 & 0.001 \\
$\mathrm{FO}$ & 0.000 & 0.000 & 0.000 \\
$\mathrm{P}_{2}$ & 0.001 & 0.000 & 0.002 \\
$\mathrm{~S}_{2}$ & 0.000 & 0.000 & 0.000 \\
$\mathrm{ClO}$ & 0.000 & 0.000 & 0.000 \\
$\mathrm{~N}_{2} \mathrm{O}$ & 0.000 & & \\
$\mathrm{NO}_{2}$ & 0.000 & & \\
$\mathrm{O}_{3}$ & 0.003 & 0.001 & 0.005 \\
$\mathrm{~F}_{2} \mathrm{O}$ & 0.001 & & \\
$\mathrm{~S}_{2} \mathrm{O}$ & 0.000 & & \\
$\mathrm{~S}_{3}$ & 0.000 & 0.001 & 0.001 \\
$\mathrm{ClNO}$ & 0.000 & & \\
$\mathrm{Cl}_{2} \mathrm{O}$ & 0.000 & & \\
\hline
\end{tabular}


3.10 Post-CCSD(T) excitations as a whole. Finally, it is of interest to examine the basis set convergence of post-CCSD(T) excitations as a whole. Table 15 lists the contribution of post$\operatorname{CCSD}(\mathrm{T})$ contributions (up to CCSDTQ5(6)) to the total atomization energy for the set of seven diatomic molecules. The reference values are taken as: $[\mathrm{T}-(\mathrm{T})] / \mathrm{V}\{5,6\} \mathrm{Z}+$ $(\mathrm{Q}) / \mathrm{V}\{\mathrm{Q}, 5\} \mathrm{Z}+[\mathrm{Q}-(\mathrm{Q})] / \mathrm{V}\{\mathrm{T}, \mathrm{Q}\} \mathrm{Z}+(5) / \mathrm{V}\{\mathrm{D}, \mathrm{T}\} \mathrm{Z}+[5-(5)] / \mathrm{V}\{\mathrm{D}, \mathrm{T}\} \mathrm{Z}+(6) / \mathrm{VDZ}(4 \mathrm{~s} 3 \mathrm{p} 1 \mathrm{~d})$. Relative to these CBS values the VDZ(3s2p) basis set attains a large RMSD of $0.83 \mathrm{kcal} \mathrm{mol}^{-}$ ${ }^{1}$. Inclusion of the $\mathrm{d}$ functions in the VDZ basis set reduces the RMSD by $66 \%$ to $0.28 \mathrm{kcal}$ $\mathrm{mol}^{-1}$. Thus, it is clear that calculating of the post-CCSD(T) contributions as a whole benefits from a significant degree of error cancelation. For example, the VDZ basis set gives RMSDs close to $1 \mathrm{kcal} \mathrm{mol}^{-1}$ for the $\mathrm{T}-(\mathrm{T})$ and $(\mathrm{Q})$ components (Tables 2-4). Addition of $\mathrm{s}$ and $\mathrm{p}$ functions in the $\operatorname{VDZ}(4 \mathrm{~s} 3 \mathrm{p} 1 \mathrm{~d})$ basis set further reduces the RMSD to $0.17 \mathrm{kcal} \mathrm{mol}^{-1}$. However, in order to obtain an RMSD smaller than $0.1 \mathrm{kcal} \mathrm{mol}^{-1}$ with a single basis set one has to calculate all the post-CCSD(T) excitations with the VTZ basis set. This is of course not a viable option for systems with more than 1-2 non-hydrogen atoms, and illustrates the need for using efficient post-CCSD(T) composite approaches. ${ }^{3,4,5,6,7,8,38}$ The preceding sections suggest that calculating the post-CCSD(T) in the following way would be a cost effective approach:

$[\mathrm{T}-(\mathrm{T})] / \mathrm{V}\{\mathrm{D}, \mathrm{T}\} \mathrm{Z}+(\mathrm{Q}) / \mathrm{V}\{\mathrm{VDZ}(4 \mathrm{~s} 3 \mathrm{p} 1 \mathrm{~d}), \mathrm{T}\} \mathrm{Z}+1.1 \times[\mathrm{Q}-(\mathrm{Q})] / \mathrm{VDZ}+(5) / \mathrm{VDZ}(3 \mathrm{~s} 2 \mathrm{p})+[5-$ $(5)] / \operatorname{VDZ}(3 \mathrm{~s} 2 \mathrm{p})+(6) / \mathrm{VDZ}(3 \mathrm{~s} 2 \mathrm{p})$

where the $\mathrm{T}-(\mathrm{T})$ and $(\mathrm{Q})$ components are extrapolated with $\alpha=2.7$ and 2.3, respectively. This approach results in an overall RMSD of $0.04 \mathrm{kcal} \mathrm{mol}^{-1}$ at a significantly reduced computational cost. For comparison calculating all the post-CCSD(T) contributions with the VTZ basis set results in an RMSD of $0.08 \mathrm{kcal} \mathrm{mol}^{-1}$. Finally, we note that extrapolating the 
post-CCSD(T) contribution as a whole from the VDZ and VTZ basis sets (with an effective exponent of $\alpha=4.5$ ) results in an RMSD of $0.07 \mathrm{kcal} \mathrm{mol}^{-1}$ and does not represent a significant improvement over the VTZ results.

Table 15. Convergence of post-CCSD(T) contributions as a whole (up to CCSDTQ5(6)) to the total atomization energy for the set of seven diatomic molecules. The reference TAEs (see footnote $a$ ) are listed in the last column, the tabulated values in the other columns are deviations relative to these basis-set limit values (in $\mathrm{kcal} \mathrm{mol}^{-1}$ ).

\begin{tabular}{cccccccc}
\hline Basis set & VDZ(3s2p) & VDZ & VDZ(4s3p1d) & VTZ & V\{D,T\}Z & Composite $^{b}$ & Ref. $^{a}$ \\
\hline $\mathrm{BN}$ & -1.860 & -0.023 & -0.309 & 0.014 & 0.022 & 0.022 & -0.408 \\
$\mathrm{C}_{2}$ & -0.801 & 0.326 & 0.086 & 0.198 & 0.174 & -0.037 & 0.401 \\
$\mathrm{O}_{2}$ & 0.492 & 0.449 & 0.065 & 0.058 & -0.018 & -0.076 & 0.641 \\
$\mathrm{FO}$ & 0.300 & 0.310 & 0.019 & 0.016 & -0.041 & -0.026 & 0.821 \\
$\mathrm{P}_{2}$ & 0.615 & 0.324 & 0.256 & 0.057 & 0.006 & -0.053 & 0.675 \\
$\mathrm{~S}_{2}$ & 0.191 & 0.179 & 0.109 & 0.034 & 0.006 & -0.041 & 0.476 \\
$\mathrm{ClO}$ & -0.114 & 0.021 & -0.077 & -0.047 & -0.060 & -0.015 & 0.736 \\
\hline $\mathrm{RMSD}^{c, d}$ & 0.833 & 0.278 & 0.165 & 0.084 & 0.072 & 0.043 & \\
$\mathrm{MAD}^{c, d}$ & 0.625 & 0.233 & 0.131 & 0.061 & 0.047 & 0.039 & \\
$\mathrm{MSD}^{c, d}$ & -0.168 & 0.226 & 0.021 & 0.047 & 0.013 & -0.032 & \\
\hline
\end{tabular}

${ }^{a}$ The post-CCSD(T)/CBS reference vales are taken as: $[\mathrm{T}-(\mathrm{T})] / \mathrm{V}\{5,6\} \mathrm{Z}+(\mathrm{Q}) / \mathrm{V}\{\mathrm{Q}, 5\} \mathrm{Z}+[\mathrm{Q}-(\mathrm{Q})] / \mathrm{V}\{\mathrm{T}, \mathrm{Q}\} \mathrm{Z}+$ $(5) / \mathrm{V}\{\mathrm{D}, \mathrm{T}\} \mathrm{Z}+[5-(5)] / \mathrm{V}\{\mathrm{D}, \mathrm{T}\} \mathrm{Z}+(6) / \mathrm{VDZ}(4 \mathrm{~s} 3 \mathrm{p} 1 \mathrm{~d})$.

${ }^{b}$ These vales are taken as: $[\mathrm{T}-(\mathrm{T})] / \mathrm{V}\{\mathrm{D}, \mathrm{T}\} \mathrm{Z}+(\mathrm{Q}) / \mathrm{V}\{\mathrm{VDZ}(4 \mathrm{~s} 3 \mathrm{p} 1 \mathrm{~d}), \mathrm{T}\} \mathrm{Z}+1.1 \times[\mathrm{Q}-(\mathrm{Q})] / \mathrm{VDZ}+(5) / \mathrm{VDZ}(3 \mathrm{~s} 2 \mathrm{p})$ $+[5-(5)] / \operatorname{VDZ}(3 \mathrm{~s} 2 \mathrm{p})+(6) / \mathrm{VDZ}(3 \mathrm{~s} 2 \mathrm{p})$, where the T-(T) component is extrapolated with $\alpha=2.7$ and the $(\mathrm{Q})$ component is extrapolated with $\alpha=2.3$.

${ }^{c}$ See footnote $a$ to Table 2 .

${ }^{d}$ Error statistics with respect to the reference values listed in the last column.

\section{Conclusions}

We have examined the basis set convergence of post-CCSD(T) contributions to the total atomization energies near (or at) the one-particle basis-set limit for a diverse set of 21 challenging molecules. We considered iterative coupled cluster contributions up to connected septuples, CCSDTQ567. The set of 21 diatomic, triatomic, and tetra-atomic molecules spans the gamut from molecules dominated by moderate nondynamical correlation (e.g., FO, $\mathrm{ClO}$, $\mathrm{NO}_{2}, \mathrm{~S}_{2} \mathrm{O}, \mathrm{N}_{2} \mathrm{C}_{2}$, and $\mathrm{P}_{4}$ ) to systems dominated by strong nondynamical correlation (e.g., $\mathrm{BN}$, $\mathrm{C}_{2}, \mathrm{FO}_{2}, \mathrm{O}_{3}, \mathrm{ClOO}$, and $\mathrm{S}_{4}$ ). Our main conclusions can be summarized as follows: 
$>\quad$ The CCSDT-CCSD(T) component. The V $\{\mathrm{T}, \mathrm{Q}\} \mathrm{Z}$ extrapolation with an effective exponent of $\alpha=2.35$ provides near basis-set limit results, with an RMSD of merely 0.009 kcal $\mathrm{mol}^{-1}$ relative to $\mathrm{V}\{5,6\} \mathrm{Z}$ extrapolations. The computationally more economical $\mathrm{V}\{\mathrm{D}, \mathrm{T}\} \mathrm{Z}$ extrapolation with an effective exponent of $\alpha=2.7$ seems to be the most cost effective approach, resulting in an RMSD of $0.09 \mathrm{kcal} \mathrm{mol}^{-1}$ relative to $\mathrm{V}\{\mathrm{T}, \mathrm{Q}\} \mathrm{Z}$ extrapolations for a wide range of 21 challenging systems. Nevertheless, the $\mathrm{V}\{\mathrm{D}, \mathrm{T}\} \mathrm{Z}$ extrapolation should be used with caution for systems containing multiple second-row atoms, for which large deviations may be obtained. For example, deviations of +0.17 and -0.29 kcal $\mathrm{mol}^{-1}$ are obtained for $\mathrm{S}_{4}$ and $\mathrm{P}_{4}$, respectively. Exclusion of these two systems from the error statistics results in an RMSD of $0.05 \mathrm{kcal} \mathrm{mol}^{-1}$ for a set of 19 challenging systems.

The CCSDT(Q)-CCSDT component. Similarly to the T-(T) component, the $\mathrm{V}\{\mathrm{T}, \mathrm{Q}\} \mathrm{Z}$ extrapolation (with $\alpha=3.0$ ) fairs very well against basis-set limit $\mathrm{V}\{5,6\} \mathrm{Z}$ results, with an RMSD of $0.014 \mathrm{kcal} \mathrm{mol}^{-1}$. Using the $\mathrm{V}\{\mathrm{T}, \mathrm{Q}\} \mathrm{Z}$ results, which we were able to obtain for the entire set of 21 molecules, we obtain a somewhat disappointing RMSD of $0.16 \mathrm{kcal}$ $\mathrm{mol}^{-1}$ for the $\mathrm{V}\{\mathrm{D}, \mathrm{T}\} \mathrm{Z}$ extrapolation (with $\alpha=3.0$ ). Optimizing the exponent results in $\alpha=$ 2.4 and an RMSD of $0.13 \mathrm{kcal} \mathrm{mol}^{-1}$. However, this performance can be significantly improved at no additional computational cost by replacing the VDZ basis set with the VDZ(4s3p1d) basis set. In particular, the $\mathrm{V}\{\mathrm{D}(4 \mathrm{~s} 3 \mathrm{p} 1 \mathrm{~d}), \mathrm{T}\} \mathrm{Z}$ extrapolation (with an effective exponent of $\alpha=2.3$ ) results in an RMSD of $0.07 \mathrm{kcal} \mathrm{mol}^{-1}$. The use of the $\mathrm{V}\{\mathrm{D}(4 \mathrm{~s} 3 \mathrm{p} 1 \mathrm{~d}), \mathrm{T}\} \mathrm{Z}$ extrapolation instead of $\mathrm{V}\{\mathrm{D}, \mathrm{T}\} \mathrm{Z}$ is particularly recommended for systems containing multiple second-row atoms.

The CCSDTQ-CCSDT component as a whole. Extrapolating the CCSDTQCCSDT component from the $\mathrm{V}\{\mathrm{D}(4 \mathrm{~s} 3 \mathrm{p} 1 \mathrm{~d}), \mathrm{T}\} \mathrm{Z}$ basis set pair results in an RMSD of 0.019 
$\mathrm{kcal} \mathrm{mol}^{-1}$. However, this approach requires running the expensive CCSDTQ/VTZ calculation. A more cost-effective approach is to use equation (3), which requires running the CCSDT(Q)/VTZ and CCSDTQ/VDZ calculations. This yields an RMSD of merely 0.016 $\mathrm{kcal} \mathrm{mol}^{-1}$. An additional advantage of this approach is that it is completely free from adjustable parameters (i.e., eq. (3) uses $c=1.0$ and $\alpha=3$ ). Reducing the size of the basis set in the CCSDTQ calculation to $\operatorname{VDZ}(3 \mathrm{~s} 2 \mathrm{p})$ and using eq. 5 with $c=0.96$ results in a slight deterioration in performance at a significantly lower computational cost. In particular, this approach yields an RMSD of $0.026 \mathrm{kcal} \mathrm{mol}^{-1}$. For larger systems where the $\operatorname{CCSDT}(\mathrm{Q}) / \mathrm{VTZ}$ calculation is prohibitive, we recommend calculating the $(\mathrm{Q})$ contribution with the $\operatorname{VDZ}(4 \mathrm{~s} 3 \mathrm{p} 1 \mathrm{~d})$ basis set and the $\mathrm{Q}-(\mathrm{Q})$ contribution with the $\operatorname{VDZ}(3 \mathrm{~s} 2 \mathrm{p})$ basis set, and scaling this result by 1.3. This approach yields an RMSD of $0.251 \mathrm{kcal} \mathrm{mol}^{-1}$ for a set of 21 challenging systems. However, it must be used with caution for systems containing many second-row atoms (e.g., $\mathrm{S}_{3}, \mathrm{P}_{4}$, and $\mathrm{S}_{4}$ ).

$>\quad$ The CCSDTQ(5)-CCSDTQ component. The VDZ(3s2p) basis set is a very costeffective basis set for calculating the (5) component. For a set of 17 systems for which we were able to obtain near basis-set-limit results with the VDZ(4s3p1d) basis set, the VDZ(3s2p) attains an RMSD of $0.047 \mathrm{kcal} \mathrm{mol}^{-1}$, after the strongly multireference BN system is excluded. The (5)/VDZ(3s2p) component also shows fairly good performance $\left(\mathrm{RMSD}=0.068 \mathrm{kcal} \mathrm{mol}^{-1}\right)$ relative to the CCSDTQ5 - CCSDTQ component. This is due to error cancelation between the neglect of the fully iterative quintuple excitations and basis set incompleteness errors. Nevertheless, for multireference systems the VDZ(3s2p) basis set can lead to fairly large errors, in these cases the VDZ basis set is recommended. 
$>\quad$ The CCSDTQ56 - CCSDTQ5 component. The connected sextuple excitations are still chemically significant and can reach up to $0.07 \mathrm{kcal} \mathrm{mol}^{-1}$ for strongly multireference systems. This contribution to the TAE is captured fairly accurately at the (6)/VDZ(3s $2 p)$ level.

$>\quad$ The CCSDTQ567 - CCSDTQ56 component. As expected these contributions are practically nil for all the systems including the strongly multireference ones. The largest CCSDTQ567 - CCSDTQ56 contributions to the TAE are obtained for BN (0.003), $\mathrm{C}_{2}$ (0.004), and $\mathrm{O}_{3}\left(0.005 \mathrm{kcal} \mathrm{mol}^{-1}\right)$.

\section{SUPPLEMENTARY MATERIAL}

See supplementary material for the optimized geometries for all the structures (Table S1); overview of the magnitude and basis-set convergence of the CCSDTQ(5)-CCSDTQ contribution to the total atomization energy for the set of 21 molecules (Table S2); and overview of the magnitude and basis-set convergence of the CCSDTQ5-CCSDTQ(5) contribution to the total atomization energy for the set of 21 molecules (Table S3); CPUtimes and number of amplitudes involved in some of the larger calculations reported in the present study (Table S4).

\section{ACKNOWLEDGMENTS}

This research was undertaken with the assistance of resources from the National Computational Infrastructure (NCI), which is supported by the Australian Government. We also acknowledge system administration support provided by the Faculty of Science at the University of Western Australia to the Linux cluster of the Karton group. We gratefully acknowledge an Australian Research Council (ARC) Future Fellowship (FT170100373). 


\section{REFERENCES}

${ }^{1}$ I. Shavitt, R. J. Bartlett, in Many-body methods in chemistry and physics: MBPT and coupled-cluster theory, Cambridge molecular science series, Cambridge: Cambridge University Press (2009).

${ }^{2}$ R. J. Bartlett, M. Musial, Rev. Mod. Phys. 79, 291 (2007).

${ }^{3}$ A. Karton, WIREs Comput. Mol. Sci. 6, 292 (2016).

${ }^{4}$ K. A. Peterson, D. Feller, D. A. Dixon, Theor. Chem. Acc. 131, 1079 (2012).

${ }^{5}$ A. Karton, S. Daon, J. M. L. Martin, Chem. Phys. Lett. 510, 165 (2011).

${ }^{6}$ D. Feller, K. A. Peterson, D. A. Dixon, J. Chem. Phys. 129, 204105 (2008).

${ }^{7}$ T. Helgaker, W. Klopper, D. P. Tew, Mol. Phys. 106, 2107 (2008).

${ }^{8}$ A. Karton, E. Rabinovich, J. M. L. Martin, B. Ruscic, J. Chem. Phys. 125, 144108 (2006).

${ }^{9}$ M. E. Harding, J. Vázquez, B. Ruscic, A. K. Wilson, J. Gauss, J. F. Stanton, J. Chem. Phys. 128, $114111(2008)$.

${ }^{10}$ A. J. C. Varandas, Annu. Rev. Phys. Chem. 69, 177 (2018).

${ }^{11}$ F. N. N. Pansini, A. J. C. Varandas, Chem. Phys. Lett. 631-632, 70 (2015).

${ }^{12}$ F. N. N. Pansini, A. C. Neto, A. J. C. Varandas, Chem. Phys. Lett. 641, 90 (2015).

${ }^{13}$ A.J.C. Varandas, F.N.N. Pansini, J. Chem. Phys. 141, 224113 (2014).

${ }^{14}$ P. R. Spackman, A. Karton, AIP Adv. 5, 057148 (2015).

${ }^{15}$ D. Feller, J. Chem. Phys. 138, 074103 (2013).

${ }^{16}$ D. S. Ranasinghe, G. A. Petersson, J. Chem. Phys. 138, 144104 (2013).

${ }^{17}$ A. Karton, J. M. L. Martin, J Chem Phys, 136, 124114 (2012).

${ }^{18}$ D. Feller, K. A. Peterson, J. G. Hill, J. Chem. Phys. 135, 044102 (2011).

${ }^{19}$ D. Feller, K. A. Peterson, D. A. Dixon, J. Phys. Chem. A 114, 613 (2010).

${ }^{20}$ J. G. Hill, K. A. Peterson, G. Knizia, H.-J. Werner, J. Chem. Phys. 131, 194105 (2009). 
${ }^{21}$ N. DeYonker, T. R. Cundari, A. K. Wilson, in: Piecuch P, Maruani J, Delgado-Barrio G, Wilson S (Eds.), Advances in the Theory of Atomic and Molecular Systems (Progress in Theoretical Chemistry and Physics, Vol. 19), Springer Netherlands, Dordrecht, 2009 pp. $197-224$.

${ }^{22}$ E. C. Barnes, G. A. Petersson, D. Feller, K. A. Peterson, J. Chem. Phys. 129, 194115 (2008).

${ }^{23}$ D. Feller, K. A. Peterson, J. Chem. Phys. 126, 114105 (2007).

${ }^{24}$ K. Kahn, A. A. Granovsky, J. Noga, J. Comput. Chem. 28, 547 (2007).

${ }^{25}$ D. Feller, K. A. Peterson, T. D. Crawford, J. Chem. Phys. 124, 054107 (2006).

${ }^{26}$ D. W. Schwenke, J. Chem. Phys. 122, 014107 (2005).

27 J. M. L. Martin, Computational Thermochemistry: A Brief Overview of Quantum Mechanical Approaches. Annu Rep Comput Chem 2005, 1:31.

${ }^{28}$ E. F. Valeev, W. D. Allen, R. Hernandez, C. D. Sherrill, H. F. Schaefer, J. Chem. Phys. $118,8594(2003)$.

${ }^{29}$ D. Feller, D. A. Dixon, J. Chem. Phys. 115, 3484 (2001).

${ }^{30}$ T. Helgaker, W. Klopper, K. L. Bak, A. Halkier, P. Jørgensen, J. Olsen, Highly accurate ab initio computation of thermochemical data. Understanding Chemical Reactivity, Vol. 22: Quantum-Mechanical Prediction of Thermochemical Data, J. Cioslowski, ed. (Kluwer, Dordrecht, 2001), pp. 1-30.

${ }^{31}$ J. M. L. Martin, S. Parthiban, W1 and W2 theory and their variants: thermochemistry in the kJ/mol accuracy range. Understanding Chemical Reactivity, Vol. 22: Quantum-Mechanical Prediction of Thermochemical Data, J. Cioslowski, ed. (Kluwer, Dordrecht, 2001), pp. 3165.

${ }^{32}$ W. Klopper, Mol. Phys. 99, 481 (2001). 
${ }^{33}$ K. L. Bak, P. Jørgensen, J. Olsen, T. Helgaker, W. Klopper, J. Chem. Phys. 112, 9229 (2000).

${ }^{34}$ J. M. L. Martin, G. de Oliveira, J. Chem. Phys. 111, 1843 (1999).

${ }^{35}$ N. Sylvetsky, K. A. Peterson, A. Karton, J. M. L. Martin, J. Chem. Phys. 144, 214101 (2016).

${ }^{36}$ D. Feller, K. A. Peterson, B. Ruscic, Theor. Chem. Acc. 133, 1407 (2014).

${ }^{37}$ A. Karton, S. Parthiban, and J. M. L. Martin, J. Phys. Chem. A 113, 4802 (2009).

${ }^{38}$ A. Karton, P. R. Taylor, J. M. L. Martin. J Chem Phys, 127, 064104 (2007).

${ }^{39}$ A. D. Boese, M. Oren, O. Atasoylu, J. M. L. Martin, M. Kállay, J. Gauss, J. Chem. Phys. 120, 4129 (2004).

${ }^{40}$ A. Tajti, P. G. Szalay, A. G. Császár, M. Kállay, J. Gauss, E. F. Valeev, B. A. Flowers, J. Vázquez, J. F. Stanton, J. Chem. Phys. 121, 11599 (2004).

${ }^{41}$ Y. J. Bomble, J. Vázquez, M. Kállay, C. Michauk, P. G. Szalay, A. G. Császár, J. Gauss, J. F. Stanton, J. Chem. Phys. 125, 064108 (2006).

${ }^{42}$ T. A. Ruden, T. Helgaker, P. Jørgensen, J. Olsen, Chem. Phys. Lett. 371, 62 (2003).

${ }^{43}$ M. Musial, R. J. Bartlett, J. Chem. Phys. 133, 104102 (2010).

${ }^{44}$ A. J. C. Varandas, J. Chem. Phys. 131, 124128 (2009).

${ }^{45}$ P. Piecuch, M. Włoch, A. J. C. Varandas, Theor. Chem. Acc. 120, 59 (2008).

${ }^{46}$ P. Piecuch, I. S. O. Pimienta, P.-D. Fan, K. Kowalski, "New Alternatives for Accurate Electronic Structure Calculations of Potential Energy Surfaces Involving Bond Breaking” ACS Symp. Ser. 958, 37-73 (2007).

${ }^{47}$ C. D. Sherrill, P. Piecuch, J. Chem. Phys. 122, 124104 (2005).

${ }^{48}$ M. L. Abrams, C. D. Sherrill, J. Chem. Phys. 121, 9211 (2004).

${ }^{49}$ A. Dutta, C. D. Sherrill, J. Chem. Phys. 118, 1610 (2003). 
${ }^{50}$ P. Piecuch, K. Kowalski, I. S. O. Pimienta, M. J. McGuire, Int. Rev. Phys. Chem. 21, 527 (2002).

${ }^{51}$ A. Karton, N. Sylvetsky, J. M. L. Martin, J. Comput. Chem. 38, 2063 (2017).

${ }^{52}$ P. R. Spackman, D. Jayatilaka, A. Karton, J. Chem. Phys. 145, 104101 (2016).

53 MRCC, a quantum chemical program suite written by M. Kállay, et al., See also: http://www.mrcc.hu.

${ }^{54}$ Z. Rolik, L. Szegedy, I. Ladjanszki, B. Ladoczki and M. Kállay, J. Chem. Phys. 139, 094105-17 (2013).

${ }^{55}$ T. H. Dunning, J. Chem. Phys. 90, 1007 (1989).

${ }^{56}$ R. A. Kendall, T. H. Dunning, Jr., R. J. Harrison, J. Chem. Phys. 96, 6796 (1992).

${ }^{57}$ T. H. Dunning, K. A. Peterson, A. K. Wilson, J. Chem. Phys. 114, 9244 (2001). 